\title{
HISTOPATHOLOGY OF ENDOMYOCARDIAL BIOPSIES FROM PATIENTS WITH IDIOPATHIC CARDIOMYOPATHY; QUANTITATIVE EVALUATION BASED ON

\author{
MULTIVARIATE STATISTICAL ANALYSIS
}

\author{
SHINICHIRO NODA
}

$\mathbf{T}$ HOUGH considerable progress has been made in the diagnosis of heart diseases, there remains a group of heart diseases primarily affecting the myocardium, the etiology of which is obscure. Goodwin ${ }^{1,2}$ suggested a clinical definition of these diseases; 'an acute, subacute, or chronic disorder of heart muscle of unknown or obscure etiology often with associated endocardial or sometimes with pericardial involvement but not atherosclerotic in origin', and he introduced the term 'cardiomyopathy'. The research group on special disease of the Ministry of Health and Welfare, Japan, calls these diseases 'idiopathic cardiomyopathy (ICM)', defined as disorders of heart muscle of unknown etiology or association.,4 Goodwin's classification ${ }^{5}$ roughly divides such diseases into hypertrophic cardiomyopathy (HCM) and congestive cardiomyopathy (CCM). HCM is subdivided into hypertrophic non-obstructive and hypertrophic obstructive cardiomyopathy (HOCM).

The gross anatomic and histopathological findings in ICM have been described in many post-mortem studies; ${ }^{1,2,5-14}$ and, especially in HOCM, biopsies removed by myotomy or myectomy have been examined in detail. ${ }^{10-12,15,16}$ After the technique of endomyocardial biopsy ${ }^{17}$ was established, many reports appeared describ-

Key Words:

Idiopathic cardiomyopathy

Biopsied ventricular muscle

Quantitation of histological findings

Multivariate analy sis ing the lightmicroscopic, histochemical and electronmicroscopic features of ICM $16,18-31$ The gross anatomic findings of HCM are massive hypertrophy and a small ventricular cavity, often accompanied by asymmetric septal hypertrophy (ASH), 11,12,32-35 which can be detected clinically by echocardiography 32,34 Histological studies of ASH have shown marked hypertrophy and abnormal arrangement of myofibers, $29,34,35$ characterized electron-microscopically by increased cellular branching, extensive side-toside intercellular connections, widened $\mathrm{Z}$ bands associated with disoriented myofibrils and myofilaments. ${ }^{10-12,15,29,35}$ On the other hand, the gross anatomic findings of CCM are a large ventricular cavity, out of proportion to the degree of hypertrophy, often accompanied by intracardiac mural thrombi! 2,5,7-12 In lightmicroscopy the major histological changes of CCM are endocardial thickening, hypertrophy of myofibers, degeneration of myofibers and interstitial fibrosis which are thought to be non-specific findings for ICM since they are observed in other heart diseases. $4,9,10-12,23,25-28,30$ Electronmicroscopy shows a considerable excess of mitochondria, the christae of which are often being destroyed; lysosomes, lipofuscin granules, glycogen granules and dilated sarcoplasmic reticulum are also observed. $10-12,24,26,36,37$

There are inherent difficulties in the quantitation of histological findings, and many investigators have used different standards! $16,21,25-27,31$ Despite these differences, the results are similar in that histological changes in ICM are more

(Received on July 28, 1979; Accepted on September 26, 1979)

Department of Internal Medicine, Osaka Medical College, Takatsuki, Osaka, Japan 

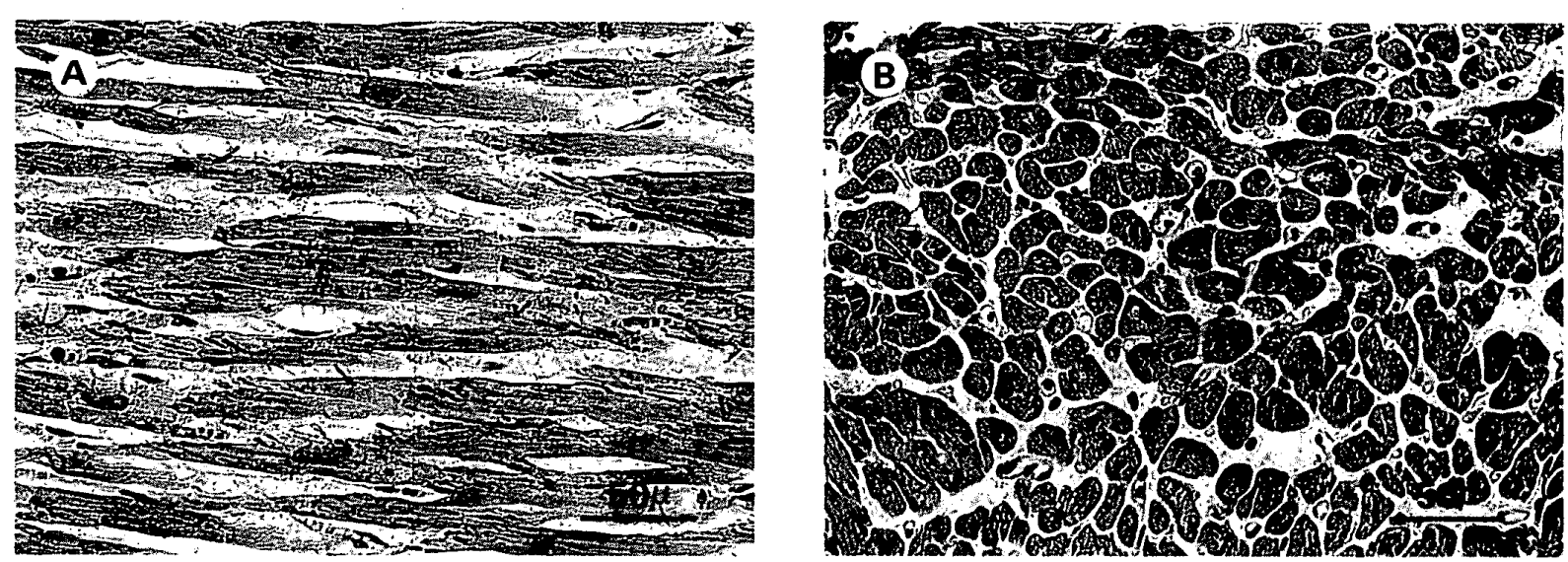

Fig. 1.
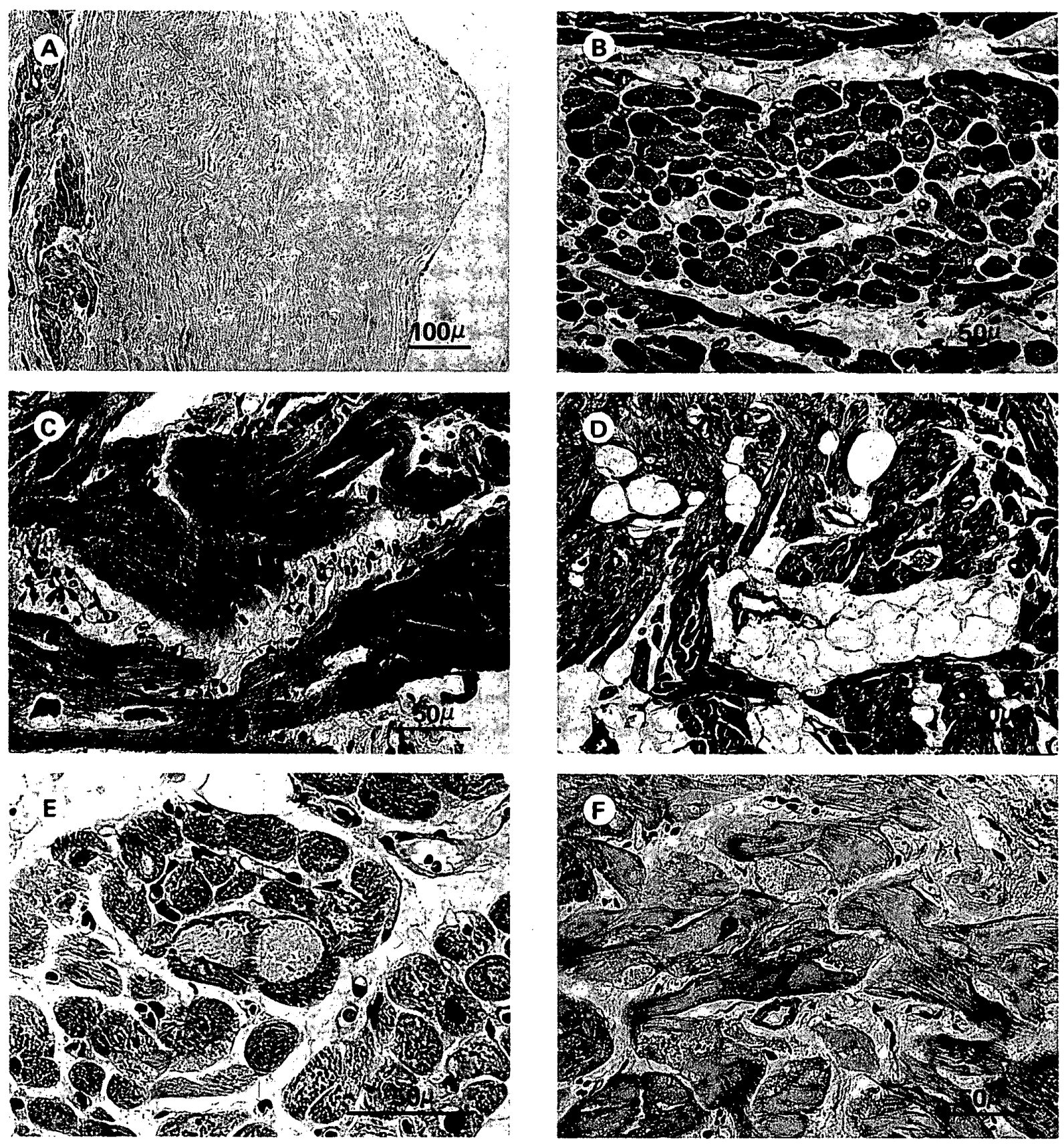

Fig. 3.

Japanese Circulation Journal Vol. 44, February r98o 
Histopathology of Endomyocardial Biopsies of Idiopathic Cardiomyopathy

1. Disarray of Myofibers

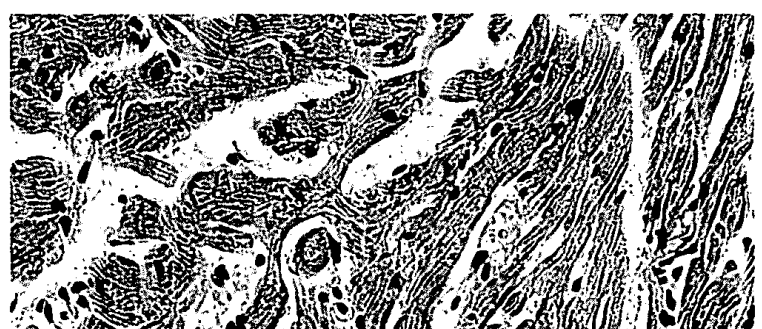

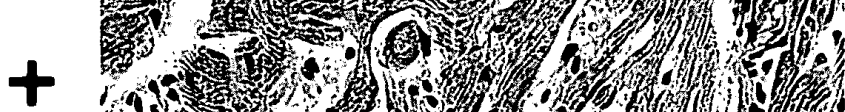

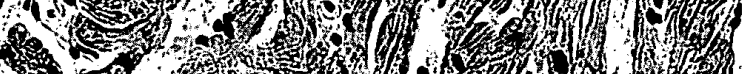
.

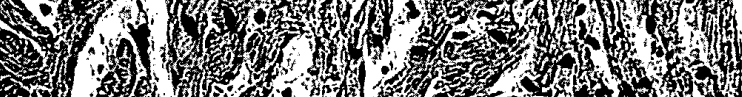

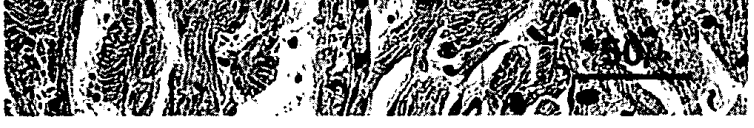

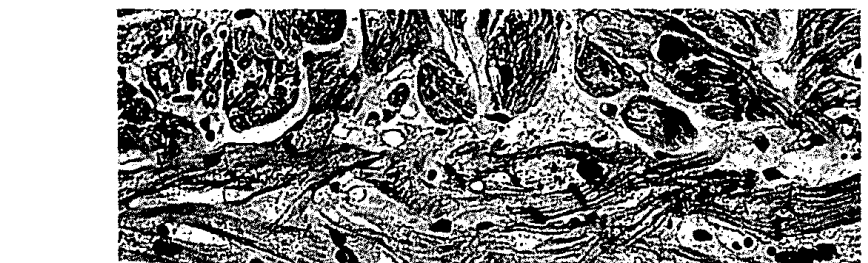

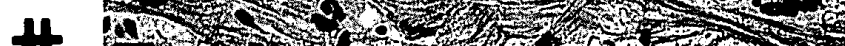
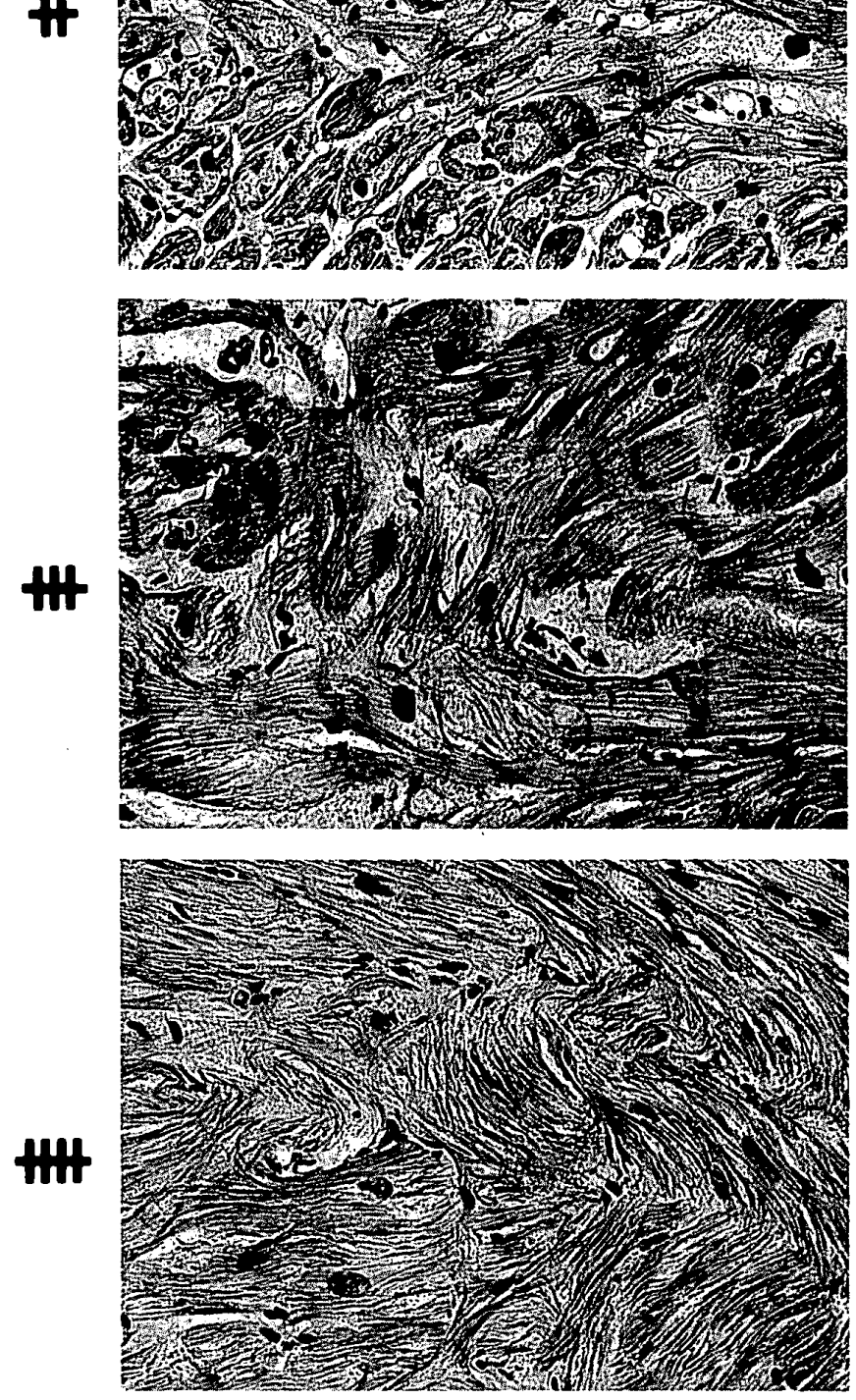

2. Hypertrophy of Myofibers
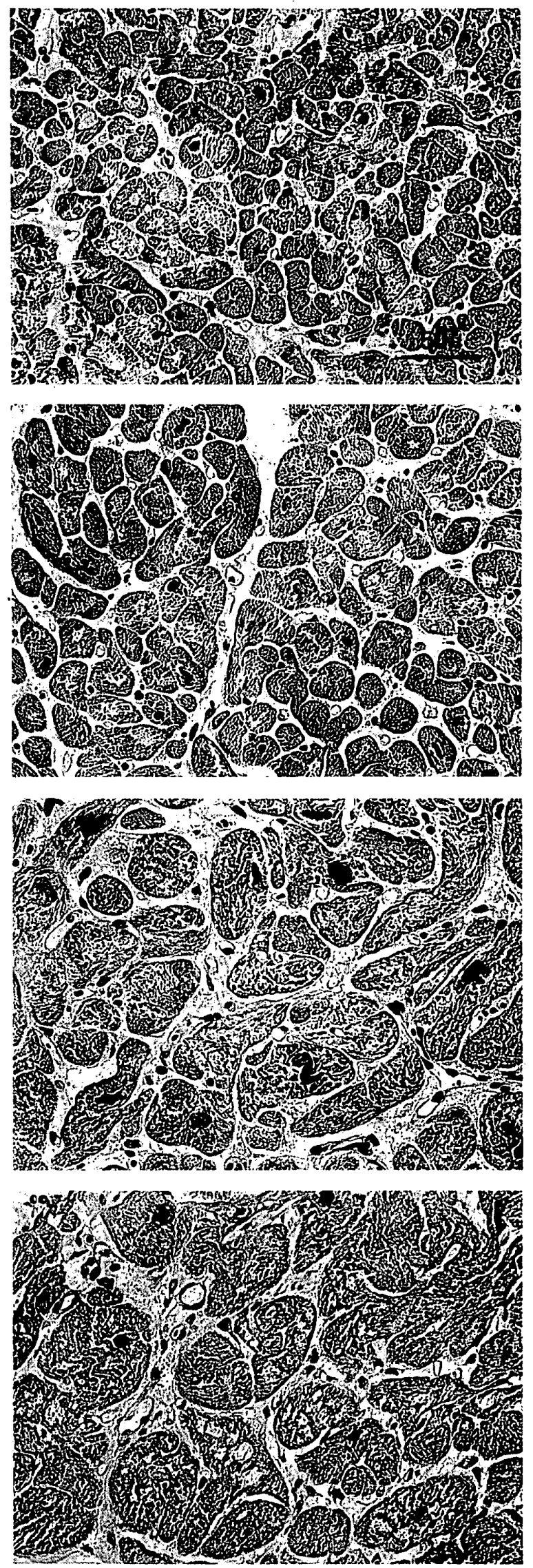

Fig.2.-1, 2 
severe and complicated than those seen in other heart diseases, such as arteriosclerotic, valvular and congenital heart diseases.

From 1964 to 1978, 144 patients with ICM were examined in our clinic. In the majority of cases, endomyocardial biopsy was obtained from the right and/or the left ventricle during cardiac catheterization. A semi-quantitative study of the histological changes was carried out on these biopsied materials. Quantitated scores of histological changes were analysed by multivariate statistical methods and utilized to evaluate the differences in histological findings between HCM and CCM, and between fatal cases and survivors. The histological findings in right ventricular biopsies (RVB) were correlated with those in left ventricular biopsies (LVB) from the same heart.

\section{MATERIALS AND METHODS}

We saw 144 patients (pts) with ICM in our clinic from 1964 to 1978 . The clinical diagnosis of ICM was made by means of careful history taking, physical and laboratory examinations, chest roentgenogram, electrocardiography, phonocardiography, cardiac catheterization and, recently, echocardiography. We excluded the numerous other heart diseases: hypertension, arteriosclerosis, valvular disease, congenital heart disease, collagen diseases and also endocrine, metabolic and neurologic disorders and blood dyscrasias. In 121 of the 144 cases endomyocardial biopsies were taken from the right ventricle and/or the left ventricle immediately after cardiac catheterization and angiocardiography. Of the 121 cases 62 (52 males and 10 females) were HCM and 59 ( 34 males and 25 females) were CCM. Echocardiography in 16 cases of HCM showed that the interventricular septum was
TABLE I NUMBER OF BIOPSIED CASES

\begin{tabular}{ccccc}
\hline Total & 121 & RVB & LVB & RVB \& LVB \\
& & 69 & 15 & 37 \\
\hline HCM & 62 & 33 & 8 & 21 \\
& $(16)$ & $(8)$ & $(2)$ & $(6)$ \\
CCM & 59 & 36 & 7 & 16 \\
\hline
\end{tabular}

HCM=hypertrophic cardiomyopathy, CCM=congestive cardiomyopathy, $R V B=$ right ventricular biopsy, $L V B=$ left ventricular biopsy. Parentheses identify cases proved to be asymmetric septal hypertrophy.

thicker than $1.3 \mathrm{~cm}$ and the ratio of its thickness to that of the posterobasal left ventricular wall was greater than 1.3, showing ASH. Eight of 16 cases of ASH were shown to be obstructive by cardiac catheterization. In 69 cases biopsies were from the right ventricle (RV), in 15 from the left ventricle (LV) and in 37 from both right and left ventricles (Table I). The mean age for $\mathrm{HCM}$ was 30 years (range 14 to 57 years) and for CCM 35 years (range 16 to 63 years).

Endomyocardial biopsies were obtained from the right side of the ventricular septum and/or the left ventricular free wall near the apex by a Konno-Sakakibara bioptome ${ }^{17}$ immediately after cardiac catheterization and angiocardiography. Each biopsy was divided into two pieces, one of which was processed for conventional lightmicroscopy and another for transmission electronmicroscopy. For lightmicroscopy, each biopsy was fixed in 10\% formalin, dehydrated with a series of ethanol and embedded in paraffin. From the paraffin blocks 3-5 $\mu \mathrm{m}$ thick sections were cut, stained with hematoxylin-eosin (HE), elastica-van-Gieson (EVG), Mallory-azan (MA) and PAS, and examied by lightmicroscopy.

\section{FIGURES 1 - 3 LEGENDS}

Fig.1. Normal myofibers in longitudinal section (Fig. 1-A; HE stain) and in transverse section (Fig. 1-B; HE stain), as a control (grade -) in the grading of the histological features in Fig. 2.

Fig.2. Grading standards for six major histological findings in biopsies from patients with ICM: disarray of myofibers (Fig. 2-1 ; HE stain), hypertrophy of myofibers (Fig. 2-2; HE stain), scarcity of myofibrils (Fig. 2-3 3 ; HE stain), nuclear changes (Fig. 2-4; HE stain), vacuolization (Fig. 2-5; $\mathrm{HE}$ stain) and proliferation of collagen fibers (Fig. 2-6; MA stain). Each finding should be compared with the normal control shown in Fig. 1. Photographs are of the same magnification from grade $(1+)$ to $(4+)$ for each histological finding.

Fig.3. Several histological findings in biopsies from patients with ICM: endocardial thickening ( $F$ ig. 3-A; HE stain), interstitial edema (Fig. 3-B; HE stain), cell infiltration (Fig. 3-C; HE stain), fatty infiltration (Fig. 3-D; EVG stain), basophilic degeneration (Fig. 3-E; HE stain) and deposits of peculiar substances (F ig. 3-F; HE stain). 
Several histological findings were observed, such as disarray of myofibers, hypertrophy of myofibers, scarcity of myofibrils, nuclear changes, vacuolization, proliferation of collagen fibers, endocardial thickening, interstitial edema, cell infiltration, fatty infiltration and deposition of basophilic or peculiar substance.

Grading of Histological Findings (Figs. 1, 2\&3)

For the semi-quantitative analysis of histological changes in ICM each finding, except deposits of basophilic or peculiar substance, was graded $(1+)$ to $(4+)$ depending upon the severity and the extent of the finding. Grade $(-)$ signifies no apparent change; $(1+)$, minimal degree; $(2+)$, moderate degree; $(3+)$, marked degree; $(4+)$, excessively marked degree.

1) Disarray of myofibers (Figs. 1-A \& 2-1): In the normal myocardium the muscle cells are rectangular and arranged in parallel in longitudinal sections (Fig. 1-A). In some cases of ICM, the myofibers are bizarrely shaped and run in a disorderly fashion. Grade (1+) signifies only minimal and focal myofiber disarray, while marked disorientation of myofibers extending throughout the biopsied specimen is graded (4+). Prominent myofiber disarray seen in one of every five fields with high magnification (x 400) is graded $(3 t)$. Grade $(2+)$ is intermediate between $(1+)$ and $(3+)$.

2) Hypertrophy of myofibers (Figs. 1-B \& 2-2): To evaluate the degree of hypertrophy the shortest diameters of cardiocytes were measured only in nucleated transverse sections stained with hematoxylin-eosin. One hundred cardiocytes in each biopsy were measured by an ocular micrometer disc with a linear scale and the average myofiber diameter of each specimen was calculated. According to several reports $14,16,20,21$, $28,38-40$ the normal average myofiber diameter is under $16 \mu \mathrm{m}$. Average myofiber diameters from 16.01 to $20 \mu \mathrm{m}$ are graded $(1+)$, those 20.01 to $24 \mu \mathrm{m}(2+)$, those 24.01 to $28 \mu \mathrm{m}(3+)$ and those over $28 \mu \mathrm{m}(4+)$.

3) Scarcity of myofibrils (Figs. 1-A \& 2-3): In degenerated myocardial cells myofibrils are occasionally decreased in number or absent. To identify a scarcity of myofibrils, an artifact-free area in longitudinal section should be examined since when there are excessively contracted areas the myofibrils are overstretched and appear falsely scarce. Marked scarcity of myofibrils (grade $3+$ or $4+$ ) is often accompanied by vacuoles or deposition of granular or peculiar substance (Fig.
3-F).

4) Nuclear changes (Figs. 1 \& 2-4): In myocardial cells in ICM the nuclei are often pyknotic, swollen and pleomorphic in size and shape. A mild degree of nuclear change shows only pleomorphism in shape without severe hypertrophy of myofibers or deposition of degenerative substance (grade 1+ or 2+ in Fig. 2-4). Moderate or severe changes are large, bizarre nuclei, often annular in shape or double and pyknotic; these were observed in markedly hypertrophied myofibers with or without deposition of degenerative substance (grade 3+ or 4+ in Fig. 2-4). The term 'nuclear changes' included all these features.

5) Vacuolization (Figs. $1 \& 2-5$ ) should be applied to perinuclear or other areas where myofibrils have disappeared with or without deposits of granular substance. Vacuolization often shows a perinuclear halo or a punched out area in the cytoplasm (grade 1+ or 2+ in Fig. 2-5), and in a more disorganized myocardium, vacuoles or deposits often occupy more than half the area of a muscle cell, along with loss of myofibrils (grade $4+$ in Fig. 2-5).

6) Proliferation of collagen fibers (Figs. $1 \&$ 2-6) can be easily detected on MA-stained sections and the severity and extent can be graded. Grade ( - ) signifies no apparent collagen fiber proliferation except for small islets of fibrous tissue around the capillaries and are intercellular single layer of collagenous tissue as in normal myocardium. Focal and minimal fibrosis is graded $(1+)$ and the most prominent fibrosis, covering more than half the area of the specimen is classified (4t). Grades $(2+)$ and $(3+)$ are intermed iate between $(1+)$ and $(4+)$.

In order to evaluate endocardial thickening the endocardium was measured at the thickest portion of the biopsied specimen. Physiologic endocardial thickening should be disregarded, and the site of the biopsy must be taken into consideration. According to Okada's report, ${ }^{41}$ more than $20 \mu \mathrm{m}$ in either the right or the left ventricle in adult hearts is abnormal. Endocardial thickening was graded as follows; 21 to $50 \mu \mathrm{m}$ $(1+), 51$ to $100 \mu \mathrm{m}(2+), 101$ to $200 \mu \mathrm{m}(3+)$ and over $201 \mu \mathrm{m}$ (4+) (Fig. 3-A). Interstitial edema (Fig. 3-B) mononuclear cell infiltration (Fig. 3-C) and fatty infiltration (Fig. 3-D) were also graded from $(-)$ to (4+). Accumulation of basophilic (Fig. 3-E) or peculiar substance (Fig. 3-F) was rarely observed in the biopsies and if present was called $(+)$.

All the specimens were studied by two 
3. Scarcity of Myofibrils

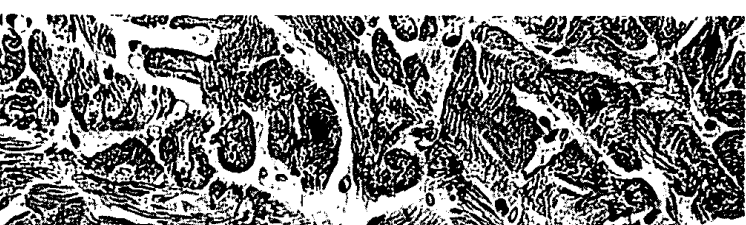

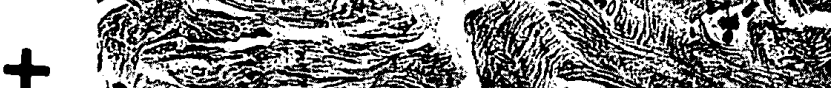

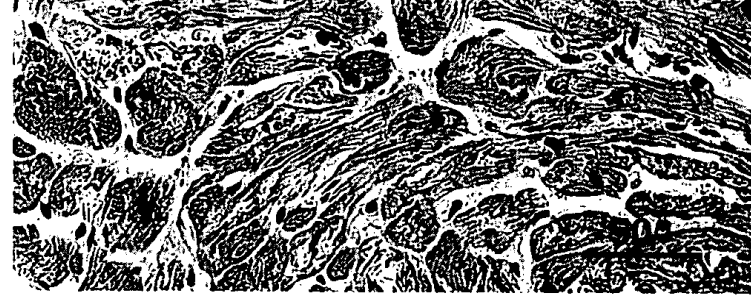

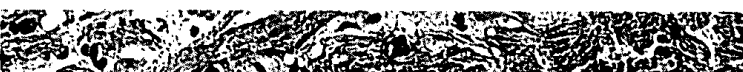
Hon

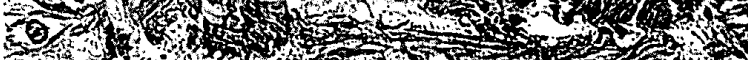

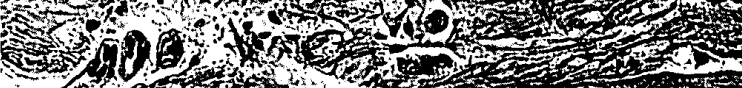

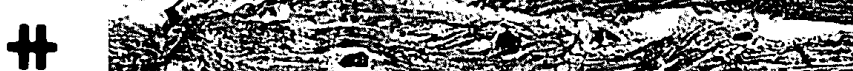

$70 \%$.

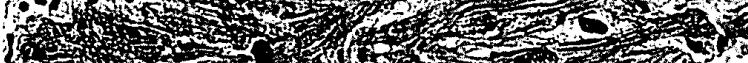

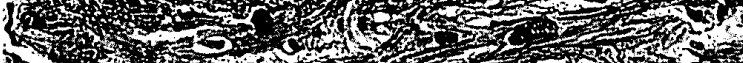

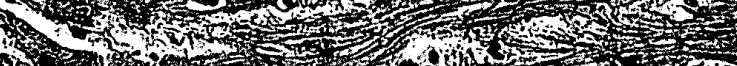

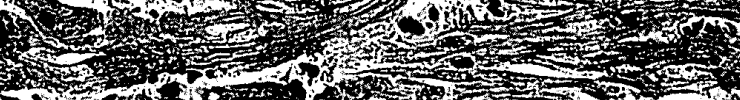

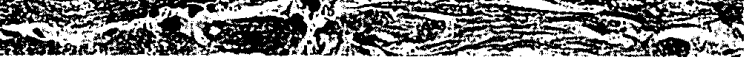

III

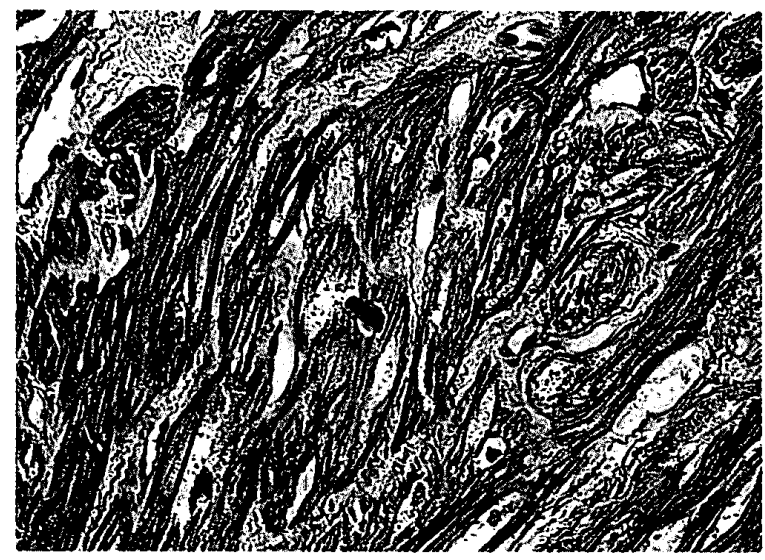

III
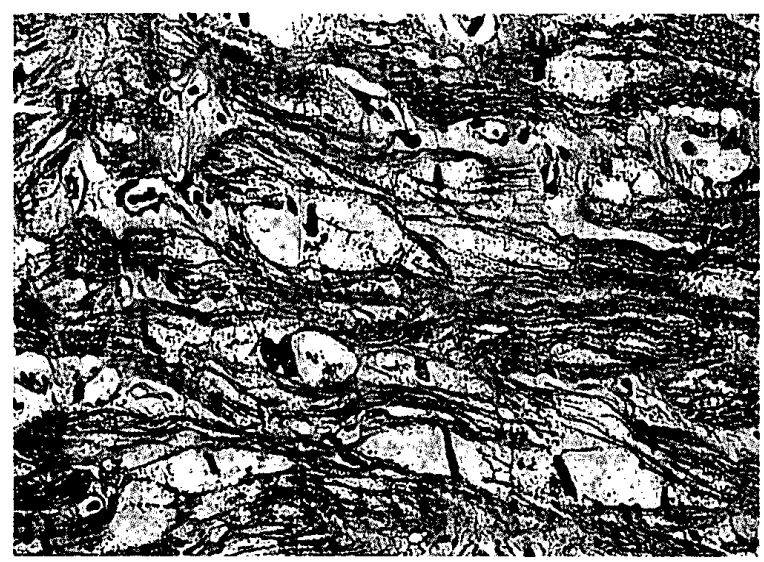

4. Nuclear Changes

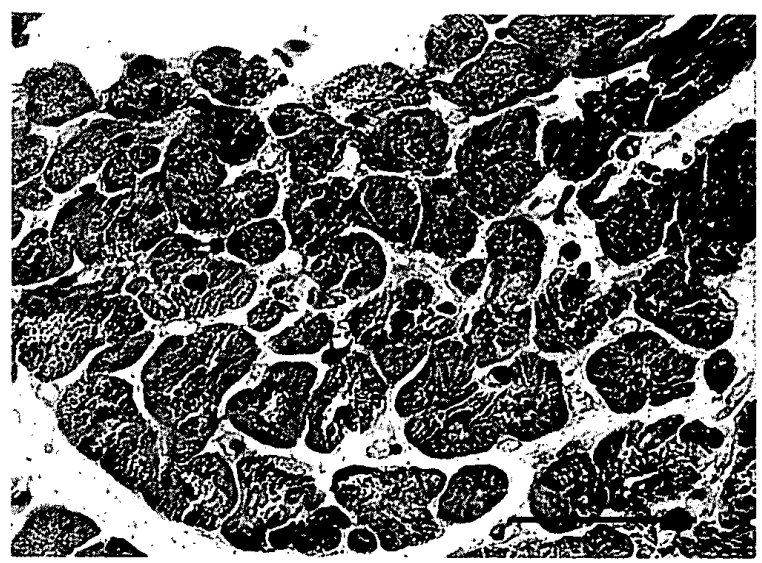

- Qu - 1 jo $94)$ (5) 15. on

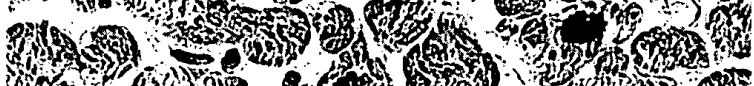
3) 4 (4) No (1)
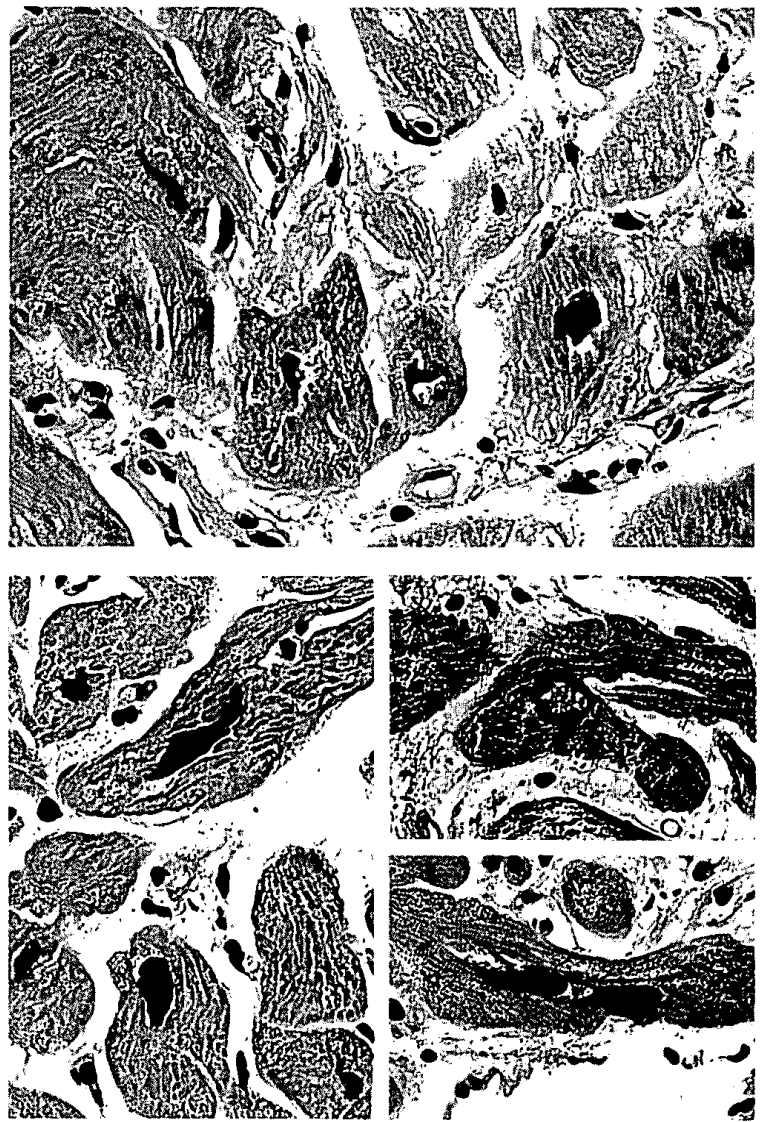

Fig.2.-3, 4 
Histopathology of Endomyocardial Biopsies of Idiopathic Cardiomyopathy

5. Vacuolization
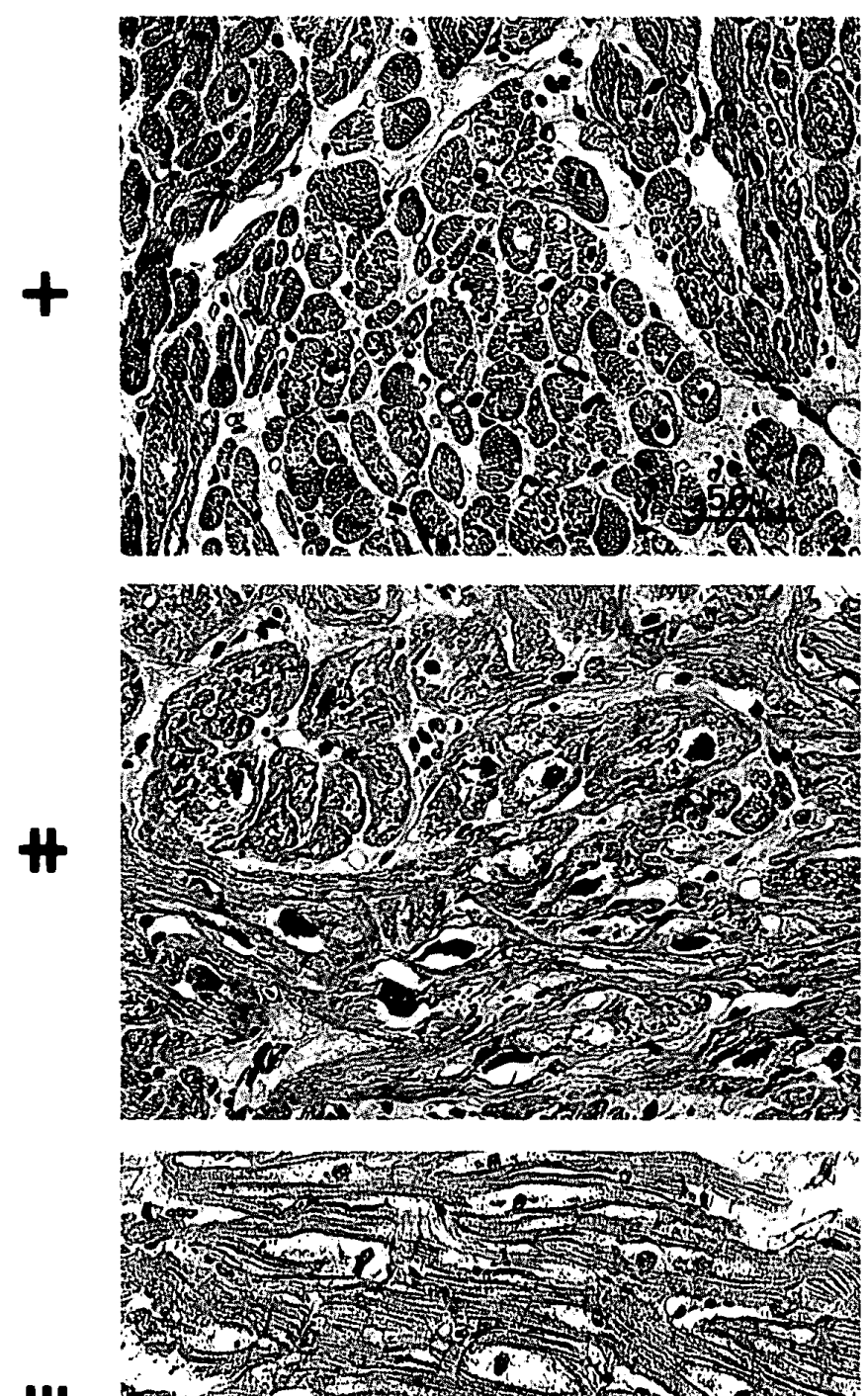

H1

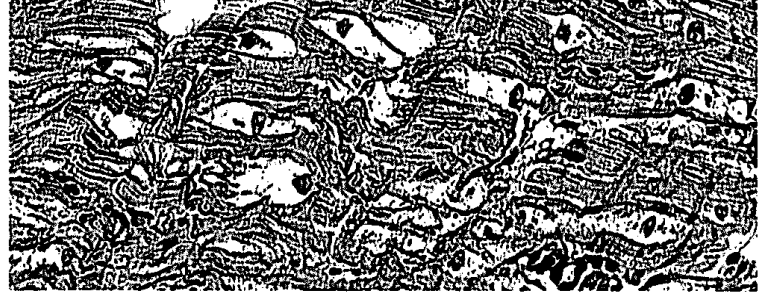

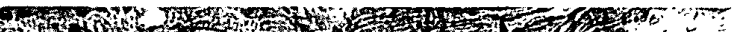

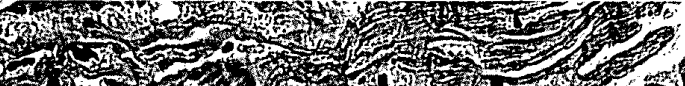

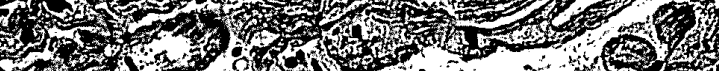

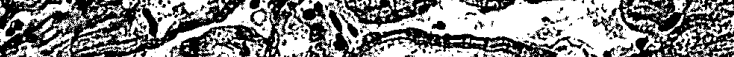

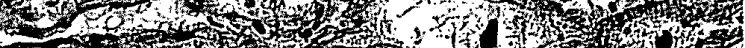

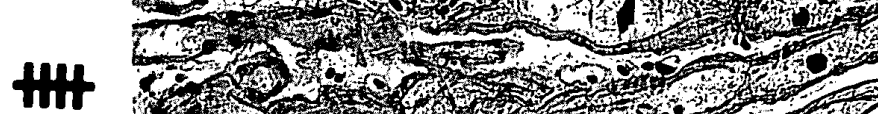

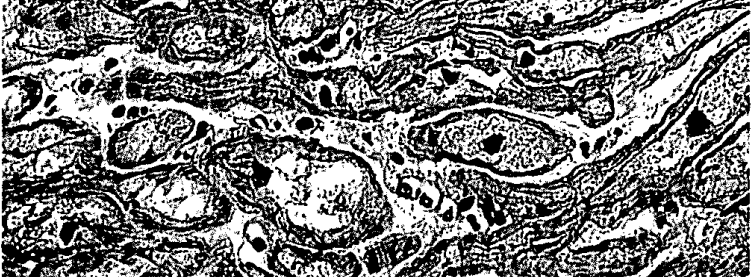

6. Proliferation of Collagen Fibers
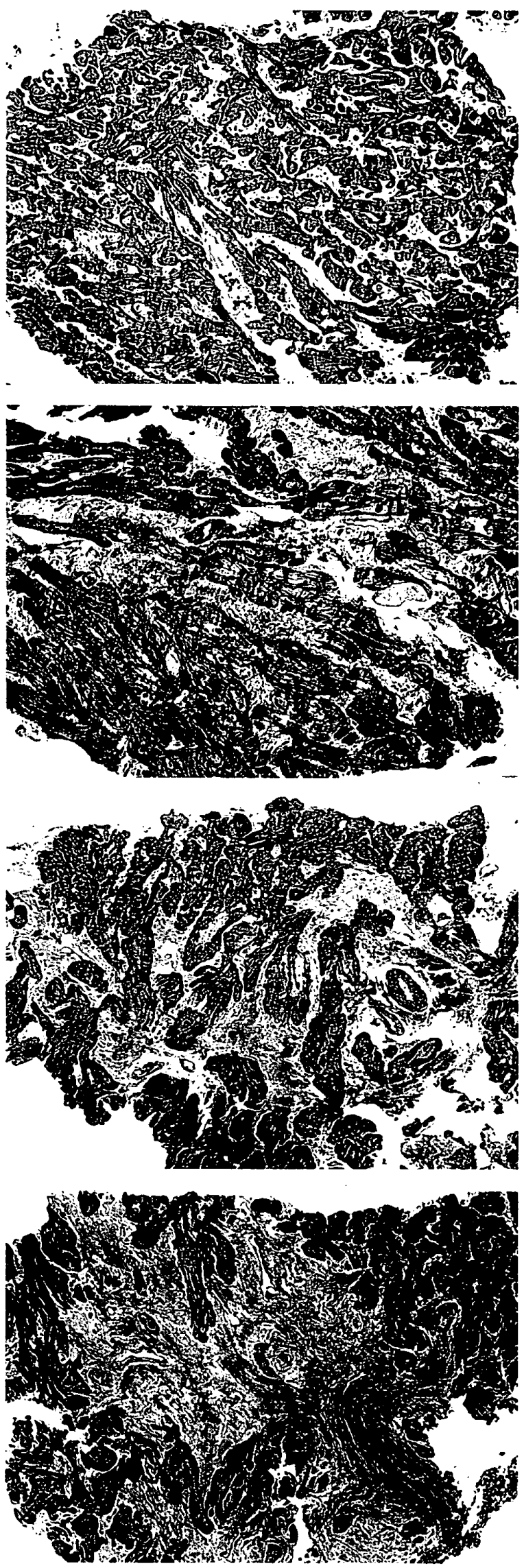

Fig.2. $-5,6$ 
observers, the author and Keishiro Kawamura, M.D. Prior to the histological study, the former had been informed of clinical diagnosis of each patient examined, whereas the latter had not. The graded scores of the histological findings virtually coincided with each other between the two observers.

\section{Method of Data Analysis}

For the statistical evaluation of the histological changes of ICM, multivariate statistical analysis was used. In this study, the more prominent and frequent first six histological features listed above were selected and analysed. For easy interpretation of analytical results, graded scores of five degrees $(-$ to $4+)$ were divided into two categories, $(+)$ and $(-)$. Category $(+)$ included grade $(2+)$ or more and category $(-)$, grade $(-)$ and (1+) for the four features, scarcity of myofibrils, nuclear changes, vacuolization and proliferation of collagen fibers. For the disarray of myofibers, category $(+)$ included grade $(3+)$ or more, and for hypertrophy of myofibers category $(+)$ signified grade $(1+)$ or more. For multivariate analysis 102 out of a total of 106 right ventricular biopsies and 49 out of a total of 52 left ventricular biopsies were used, materials which were so small that cell diameters could not be calculated being excluded. Then categorical principal component analysis, 42,43 one type of principal component analysis, ${ }^{4-46}$ was carried out with the data of these six histological findings (or six variables) in a total of 151 biopsies. Principal component analysis is defined by Marriott: ${ }^{45}$ 'The method of principal component analysis consists in transforming a set of variables $x_{1} \ldots x_{p} \quad[p=6$ in the present study] to a new set $y_{1} \ldots y_{p}$ with the following properties:

(i) Each is a linear combination of the $x$ 's; say

$$
y_{i}=a_{i 1} x_{l}+a_{i 2} x_{2}+\ldots+a_{i p} x_{p} .
$$

(ii) The sum of squares of the coefficients $\mathrm{a}_{i j}, j=1 \ldots p$, is unity.

(iii) Of all possible combinations of this type, $y_{1}$ has the greatest variance.

(vi) Of all possible combinations of this type uncorrelated with $y_{1}, y_{2}$ has the greatest variance. Similarly, $y_{3}$ has the greatest variance of combinations uncorrelated with $y_{1}$ and $y_{2}$, and so on until the complete set of $y$ 's, from $y_{1}$ to $y_{p}$, has been defined. In this way, a new set of $p$ variables is defined, uncorrelated with each other, and arranged in order of decreasing variance. The main idea behind this procedure is that the first few principal components [three principal components in this study] may well account for most of the variability in the original data, and for many purposes it may be reasonable to discard the remainder of them and so reduce the number of variables [from six to three variables in this study] that it is necessary to consider. The method is perfectly general, it involves no assumption about the original variables, no hypothesis that can be tested, no underlying model. It is simply a different, and possibly more convenient, way of expressing the same set of results.' In the present study from six variables (i.e. histological findings) three principal components could be extracted and each principal score calculated with FACOM M160AD computer system. With these principal scores the histological differences between HCM and $\mathrm{CCM}$, and between fatal cases and survivors, and the correlation of histological findings between RVB and LVB in the same patient were analysed statistically.

\section{RESULTS}

Quantitative Evaluation of Histological Findings

The frequency and severity of the histological abnormalities in RVB or LVB in both HCM and $\mathrm{CCM}$ are summarized in Table II. The histological findings in HCM and CCM were compared by Wilcoxon's rank sum test. No difference was noted except in nuclear changes, which were more frequent in CCM than in HCM at the 5 percent level. With regard to myofiber disarray, in LVB grade $(3+)$ or $(4+)$ was observed in 3 $(37.3 \%)$ out of 8 cases of ASH, in $3(13.1 \%)$ out of 13 cases of CCM, this difference was not statistically significant. However, in RVB it was found in $6(42.1 \%)$ out of 14 cases of ASH and in $8(15.5 \%)$ out of 52 cases of CCM. Thus, in RVB marked disarray of myofibers was more frequent in $\mathrm{ASH}$ than in $\mathrm{CCM}$ at the 5 percent level. The average of the mean myofiber diameters of LVB was $23.28 \mu \mathrm{m}$ (range 13.72 to $33.11 \mu \mathrm{m}$ ) in $\mathrm{HCM}$ and $22.73 \mu \mathrm{m}$ (range 17.66 to $32.71 \mu \mathrm{m}$ ) in CCM. That of RVB was 17.31 $\mu \mathrm{m}$ (range 11.30 to $27.86 \mu \mathrm{m}$ ) in HCM and 18.10 $\mu \mathrm{m}$ (range 13.13 to $25.75 \mu \mathrm{m}$ ) in CCM. These differences in myofiber diameter between HCM and $\mathrm{CCM}$ are not statistically significant in either LVB or RVB. Marked thickening of the endo cardium, graded $(3+)$ or $(4+)$, was observed in 4 cases of HCM and 4 cases of CCM. According to Okada's classification,' ${ }^{41}$ endocardial thickening in 


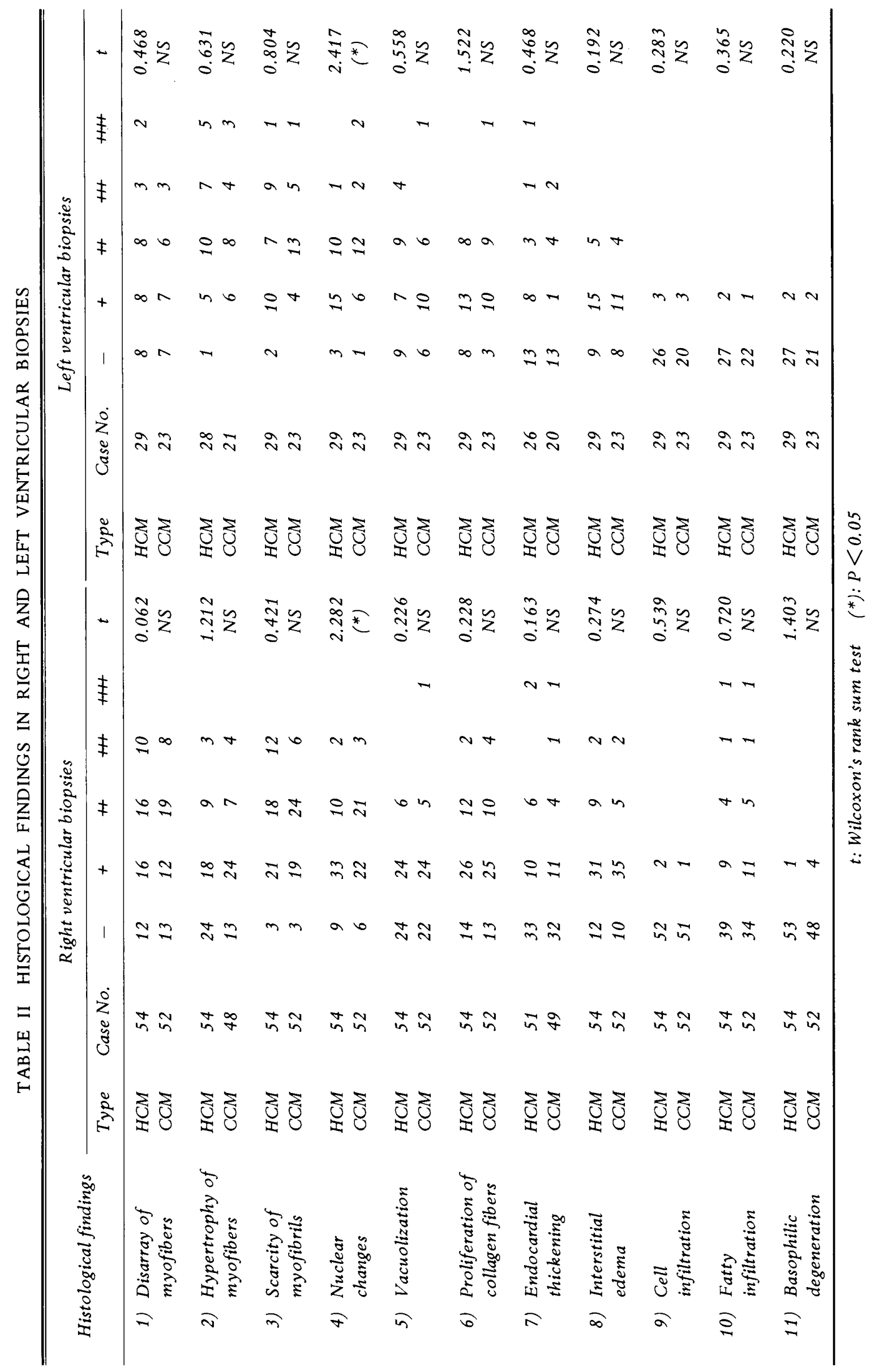


A : First Principal Component

\begin{tabular}{|c|c|c|c|c|c|c|}
\hline & $\begin{array}{l}\text { Histological } \\
\text { findings }\end{array}$ & Category & $\underset{(\substack{0 \\
\text { Sij }})}{\text { Sample size }}$ & Weight & Illustration of weight & Range \\
\hline I & $\begin{array}{l}\text { Disarray of } \\
\text { myofibers }\end{array}$ & $\dot{+}+$ & $\begin{array}{r}125(82.8) \\
26(17.2)\end{array}$ & $\begin{array}{r}17.496 \\
-38.362\end{array}$ & & 55.858 \\
\hline 2 & $\begin{array}{l}\text { Hypertrophy of } \\
\text { myof ibers }\end{array}$ & $\overline{+}+$ & $\begin{array}{r}39(25.8) \\
112(74.2)\end{array}$ & $\begin{array}{r}22.970 \\
-13.555\end{array}$ & & 36.525 \\
\hline 3 & $\begin{array}{l}\text { Scarcity of } \\
\text { myofibrils }\end{array}$ & $\dot{+}$ & $\begin{array}{l}58(38.4) \\
93(61.6)\end{array}$ & $\begin{array}{r}37.582 \\
-29.679\end{array}$ & & 67.261 \\
\hline 4 & $\begin{array}{l}\text { Nuclear } \\
\text { changes }\end{array}$ & $\dot{+}+$ & $\begin{array}{l}91(60.3) \\
60(39.7)\end{array}$ & $\begin{array}{r}31.797 \\
-39.159\end{array}$ & & 70.956 \\
\hline 5 & Vacuolization & $\dot{-}+$ & $\begin{array}{r}122(80.8) \\
29(19.2)\end{array}$ & $\begin{array}{r}9.784 \\
-20.067\end{array}$ & & 29.850 \\
\hline 6 & $\begin{array}{l}\text { Proliferation of } \\
\text { collagen fibers }\end{array}$ & $i$ & $\begin{array}{r}105(69.5) \\
46(30.5)\end{array}$ & $\begin{array}{r}25.739 \\
-38.388\end{array}$ & & 64.627 \\
\hline
\end{tabular}

\section{B : Second Principal Component}

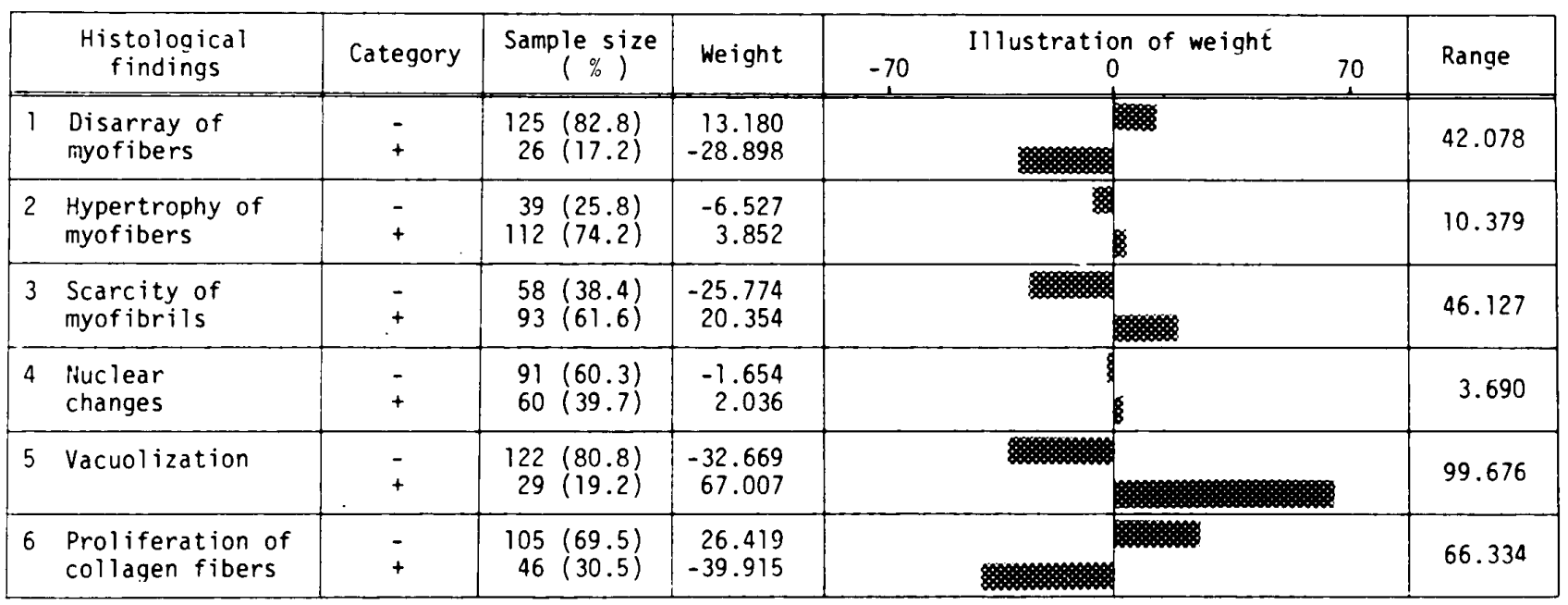

C : Third Principal Component

\begin{tabular}{|c|c|c|c|c|c|c|c|}
\hline & $\begin{array}{l}\text { Histological } \\
\text { findings }\end{array}$ & Category & $\begin{array}{c}\text { Sample size } \\
(\%)\end{array}$ & We ight & $\begin{array}{c}\text { Illustration of weight } \\
-80 \\
\end{array}$ & 80 & Range \\
\hline 1 & $\begin{array}{l}\text { Disarray of } \\
\text { myofibers }\end{array}$ & $\dot{+}$ & $\begin{array}{r}125(82.8) \\
26(17.2)\end{array}$ & $\begin{array}{r}12.427 \\
-27.247\end{array}$ & & & 39.674 \\
\hline 2 & $\begin{array}{l}\text { Hypertrophy of } \\
\text { myofibers }\end{array}$ & $\dot{+}+$ & $\begin{aligned} 39(25.8) \\
112(74.2)\end{aligned}$ & $\begin{array}{r}-77.053 \\
45.469\end{array}$ & & & 122.522 \\
\hline 3 & $\begin{array}{l}\text { Scarcity of } \\
\text { myofibrils }\end{array}$ & $\overline{+}$ & $\begin{array}{l}58(38.4) \\
93(61.6)\end{array}$ & $\begin{array}{r}17.112 \\
-13.513\end{array}$ & & & 30.625 \\
\hline 4 & $\begin{array}{l}\text { Nuclear } \\
\text { changes }\end{array}$ & $\dot{+}$ & $\begin{array}{l}91(60.3) \\
60(39.7)\end{array}$ & $\begin{array}{l}-9.176 \\
11.301\end{array}$ & & & 20.477 \\
\hline 5 & Vacuolization & $\overline{+}+$ & $\begin{aligned} 122(80.8) \\
29(19.2)\end{aligned}$ & $\begin{array}{r}8.033 \\
-16.477\end{array}$ & & & 24.510 \\
\hline 6 & $\begin{array}{l}\text { Proliferation of } \\
\text { collagen fibers }\end{array}$ & $\overline{+}$ & $\begin{aligned} & 105(69.5) \\
& 46(30.5)\end{aligned}$ & $\begin{array}{r}4.787 \\
-7.232\end{array}$ & & & 12.019 \\
\hline
\end{tabular}

Fig.4. Categorical weight of each histological finding for the first, the second or the third principal component, derived from categorical principal component analysis of 151 biopsies. For the first principal component, all six histological findings have heavy weights (Fig. 4-A); for the second, vacuolization and proliferation of collagen fibers have relatively heavy weights (Fig. 4-B); for the third, hypertrophy of myofibers has a relatively wide rage. Category $(+)$ signifies positive histological findings, whereas category $(-)$ means no apparent histological change. 


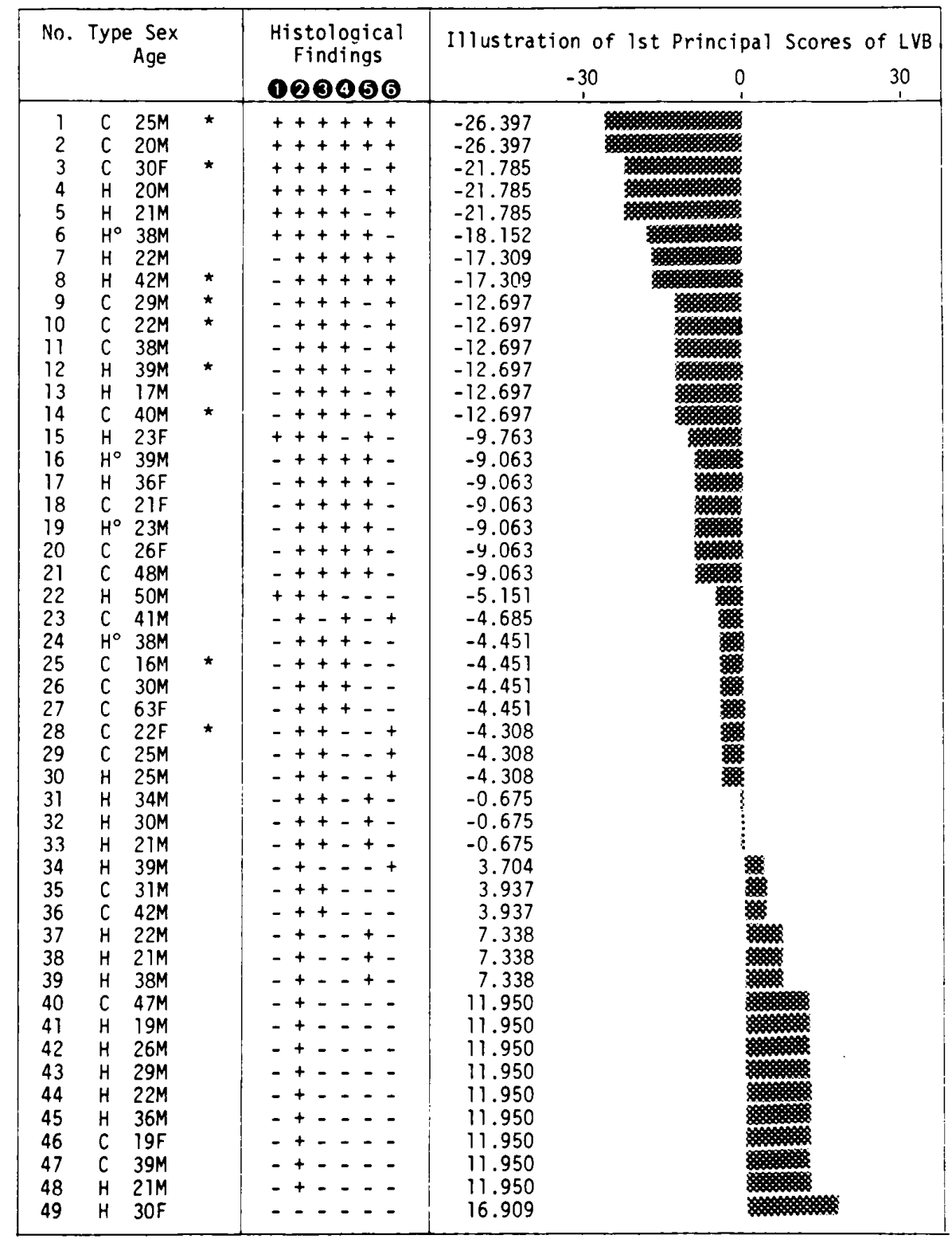

Fig.5. Illustration of the first principal scores of LVB from 49 cases ( 28 of $\mathrm{HCM}, 21$ of $\mathrm{CCM}$ ), and their original categories ( + or -) of six histological findings: (1), disarray of myofibers; 2, hypertrophy of myofibers; 3, scarcity of myofibrils; 4, nuclear changes; 5 , vacuolization; 6, proliferation of collagen fibers. $\mathrm{H}=$ hypertrophic non-obstructive cardiomyopathy, $\mathrm{H}^{\circ}=$ hypertrophic obstructive cardiomyopathy, $\mathrm{C}=$ congestive cardiomyopathy, $*=$ fatal case, $(+)=$ positive finding, $(-)=$ negative finding $($ see text).

these cases was divided into 5 types: structureless fibrosis, fibroelastosis, thickening of the subendothelial layer, thickening of all 5 layers and thickening of the subendocardial layer. Fibroelastosis was found in 3 cases of HCM and all 4 cases of CCM. There was thickening of the subendothelial layer in one case of HCM. Interstitial edema and fatty infiltration appeared more frequently in RVB than in LVB. Cell infiltration and basophilic degeneration were rarer than other histological findings. In one case of CCM both RVB and LVB revealed accumulation of peculiar degenerative substance; i.e. homogenous, partially granular, vaguely eosinophilic material in HE stained sections (Fig. 3-F). This case has been reported in detail by Takatsu, ${ }^{19}$ and the same deposits have been examined by Kawamura $^{18}$ Sakakibara $^{47}$ and Ferrans. 


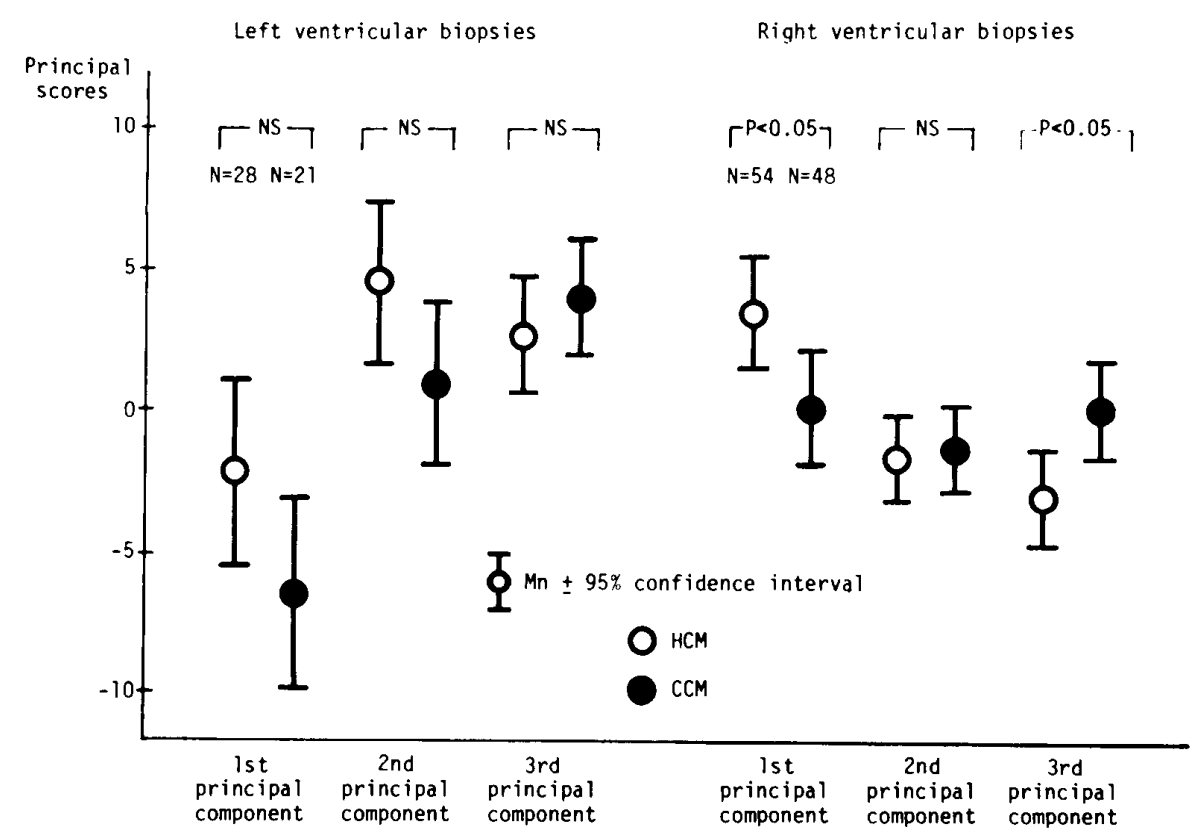

Fig.6. Differences in histological changes in LVB or RVB between $\mathrm{HCM}$ and $\mathrm{CCM}$ for the first, second or third principal component. In LVB, though the differences between HCM and $\mathrm{CCM}$ are not significant, the mean value of the first principal scores is smaller in CCM than in HCM, which means that cases of CCM to show more severe histological changes than do cases of HCM (see Fig. 4-A). In RVB, the difference between the two groups is significant for the first and the third principal component, which means that cases of CCM have more severe histological changes and more hypertrophied myofibers than do cases of HCM (see Fig. 4-A, C \& 7).

\section{Multivariate Analysis of Histological Findings}

Categorical principal component analysis was carried out with the data on the six histological findings (or six variables). Three principal components (or principal factors) can be extracted from the six variables by taking into account the magnitude of the contribution ratio of these components to the total variation of these variables. That is, about $65.1,9.5$ and 8.0 percent of the total variation of the six variables could be explained by variations of the first, second and third principal components, respectively. Fig. 4 shows the categorical weights of the first, second and third principal components corresponding to the categories of the six variables. For the first principal component, large ranges of categorical weights are obtained in all six histological findings (Fig. 4-A). Negative values are obtained as categorical weights of each variable in cases with a positive category (i.e. positive histological findings). On the other hand, in cases with a negative category (i.e. absence of histological findings), categorical weights are obtained as positive values. For the second principal component, relatively large ranges of categorical weights are obtained in two of six variables: vacuolization and proliferation of collagen fibers. As described in Fig. 4-B, a case in which vacuolization is observed has a large positive weight, whereas a case with proliferation of collagen fibers has relatively large negative weight. For the third principal component, hypertrophy of myofibers has a large range of categorical weights, but the range of each of the other five variables is relatively small (Fig. 4-C). The third principal component is characterized mainly by hypertrophy of myofibers. A positive weight is obtained in a case with hypertrophy of myofibers, whereas a case without hypertrophy of myofibers has a relatively large negative weight.

These three principal scores for each patient can be calculated by summing up the weights of the categories assigned for the patient. Fig. 5 shows the correlation between histological findings (i.e. original categories) and the first principal score of LVB in each case. Histological findings, i.e. disarray of myofibers, hypertrophy of myofibers, scarcity of myfibrils, nuclear changes, 


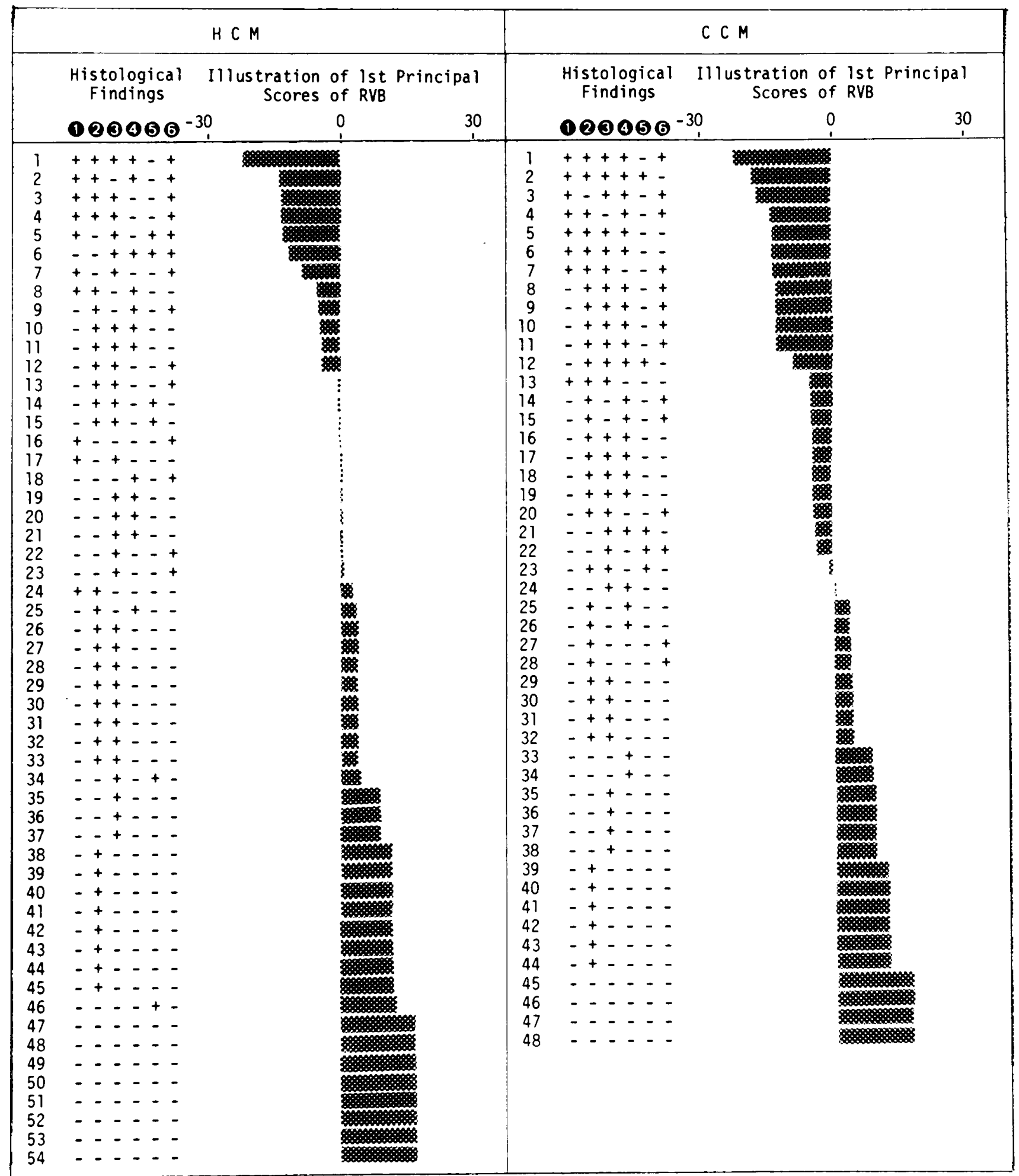

Fig.7. Illustration of the first principal scores of RVB from cases of HCM and CCM and their original categories $(+$ or - ) of six histological findings. Cases with negative values for the first principal scores (= severe histological changes) are more frequent in CCM than in HCM (see Fig. 6). Original categories (+ or - ) of six histological findings $(1-6)$ are the same as in Fig. 5.

vacuolization and proliferation of collagen fibers, are arranged in order from left to right and described as $(+)$ or $(-)$. Each case is arranged according to the ordered value of the first principal score. In cases with negative values for the first principal score many histological changes are observed, while cases with large positive values have only one or two positive histolo-

Japanese Circulation Journal Vol. 44, February 1980 


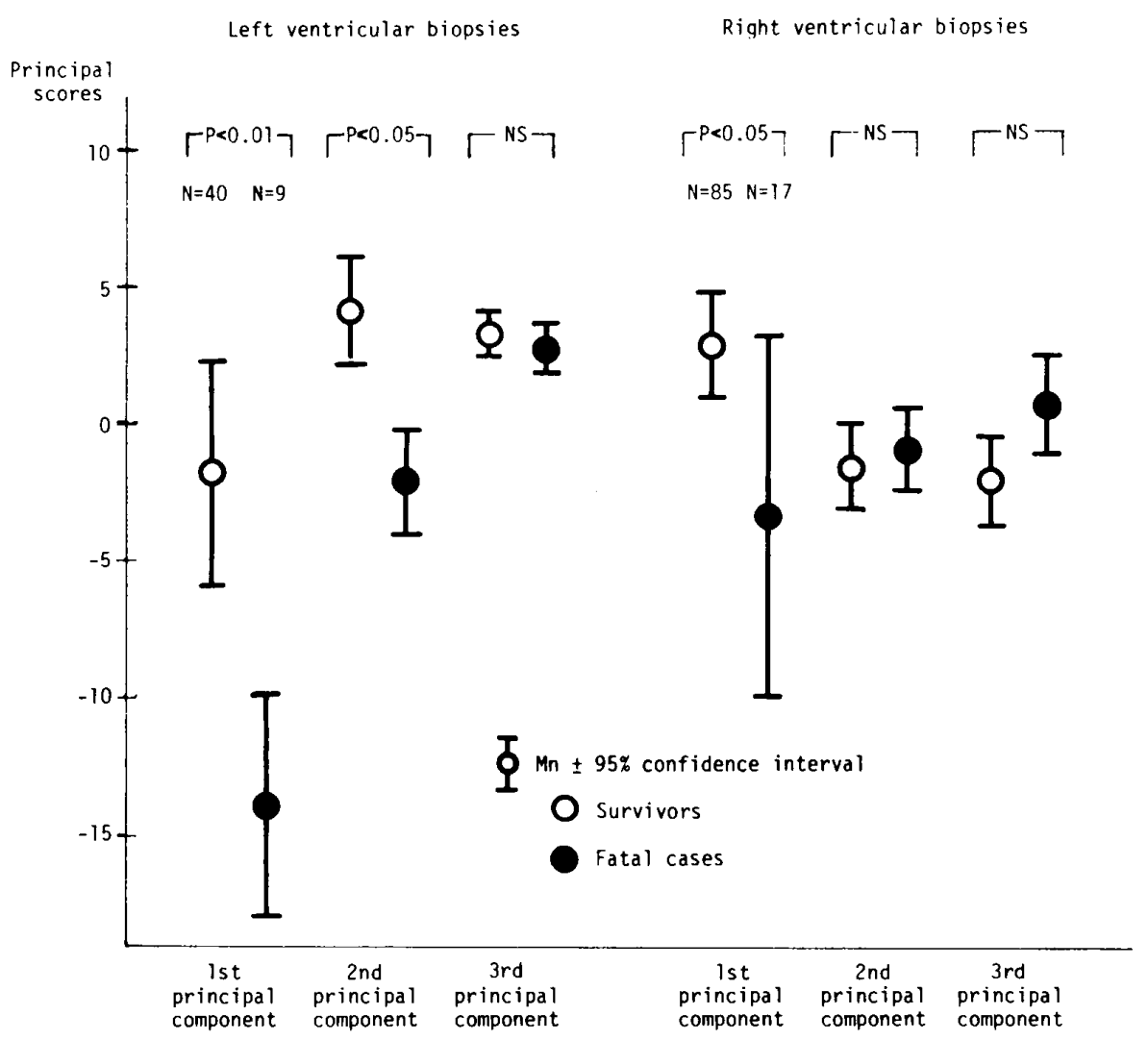

Fig.8. Differences in histological changes of LVB or RVB in survivors and fatal cases for the first, second and third principal component. In either LVB or RVB, the mean value of the first principal scores of fatal cases is smaller than that of survivors, which means that fatal cases show more severe histological changes than do survivors (see Fig. 4-A \& 9). In LVB, the average value of the second principal scores of fatal cases is smaller than that of survivors, which means that fatal cases have more prominent collagenosis but less severe vacuolization than do survivors (see Fig. 4-B \& 9).

gical findings or none. In this way, all cases can be roughly assigned to one of two groups with the zero point of the first principal score the dividing line: one with severe histological changes and one with mild histological changes. The majority of the latter show only hypertrophy of the myofibers or no significant histological change. Cases of HCM and CCM appear to be equal in number in the former group, and the majority of those in the latter are HCM. The fatal cases, all of which have negative values for the first principal scores in LVB, are in the former group.

Comparison of histological changes between HCM and CCM utilizing principal scores of LVB or RVB

To compare the histological changes of HCM with those of CCM the principal scores of each group were averaged. Fig. 6 shows the average scores of LVB or RVB from patients with HCM or CCM for the first, the second and the third principal component and their 95 percent confidence intervals. In LVB no difference between HCM and CCM was significant for the first, the second or the third principal comonent, but the mean value of the first principal score in CCM is smaller than that in HCM, which means that patients with CCM tend to have more severe histological changes than those with HCM (Figs. 4-A \& 6). On the other hand, in RVB the difference between these two groups is significant for the first and the third principal component at the 5 percent level. For the first principal component, the average score of cases of CCM is smaller than that of cases of HCM, which means that histological changes in RVB from cases of $\mathrm{CCM}$ are more severe and frequent than those in 


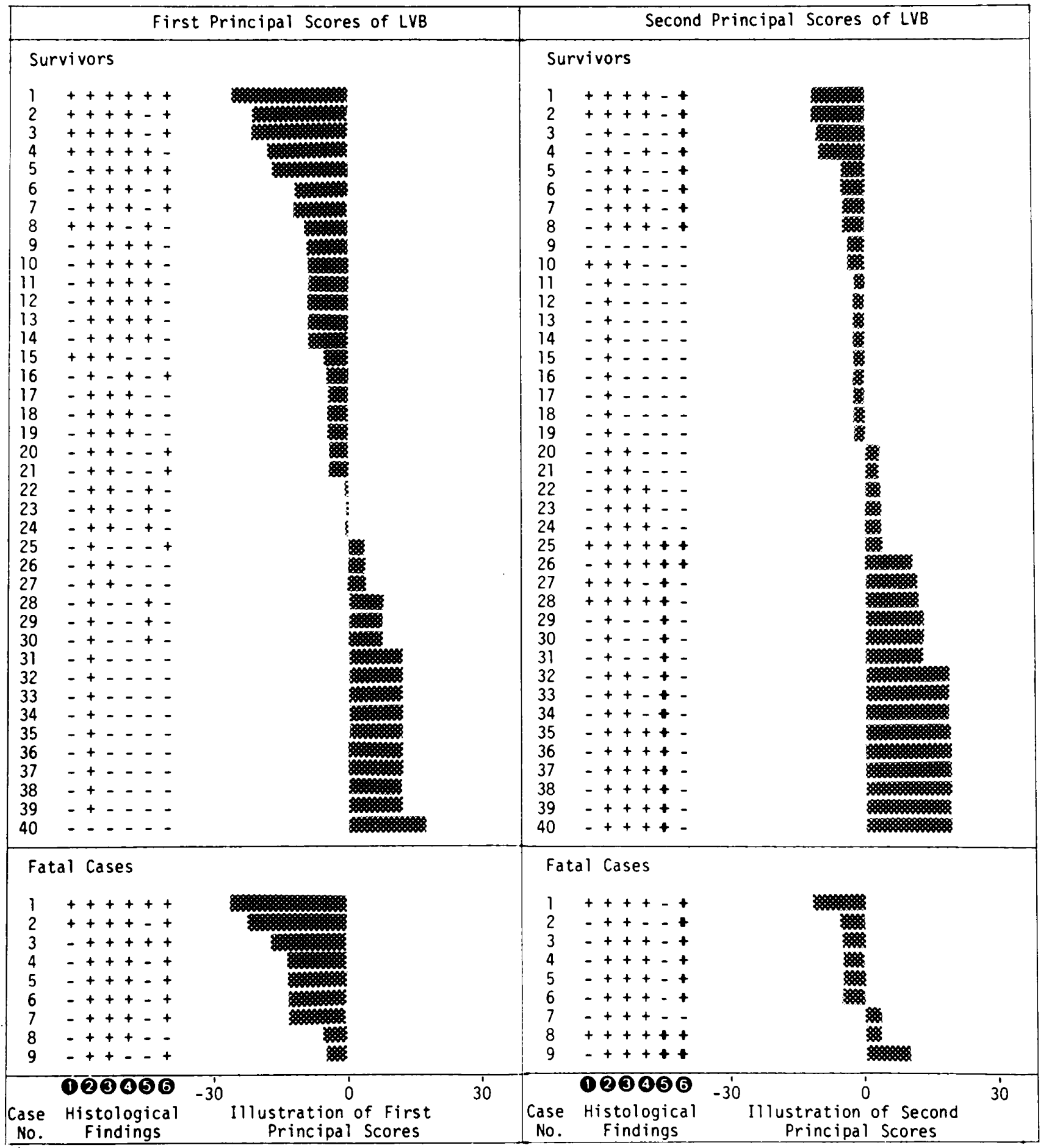

Fig.9. Illustration of the first and second principal scores of LVB from survivors and fatal cases, and original categories $(+$ or - ) of six histological findings. All fatal cases have negative first principal scores in LVB, indicating severe histological changes (see Fig. 8). Illustration of the second principal scores and original categories (+ or -) of LVB reveals that in fatal cases collagenosis (6) is more frequent but vacuolization (5) is less prominent than in survivors. Among both survivors and fatal cases, those with collagenosis (6) have no apparent vacuolization (5), while those with prominent vacuolization (5) rarely have collagenosis (6).

RVB from cases of HCM (Figs. 4-A, 6 \& 7). For the third principal component, the mean value of cases of CCM is larger than that of cases of HCM, which means that myofiber hypertrophy in RVB is more prominent in CCM than in HCM (Figs. 4-C \& 6). 


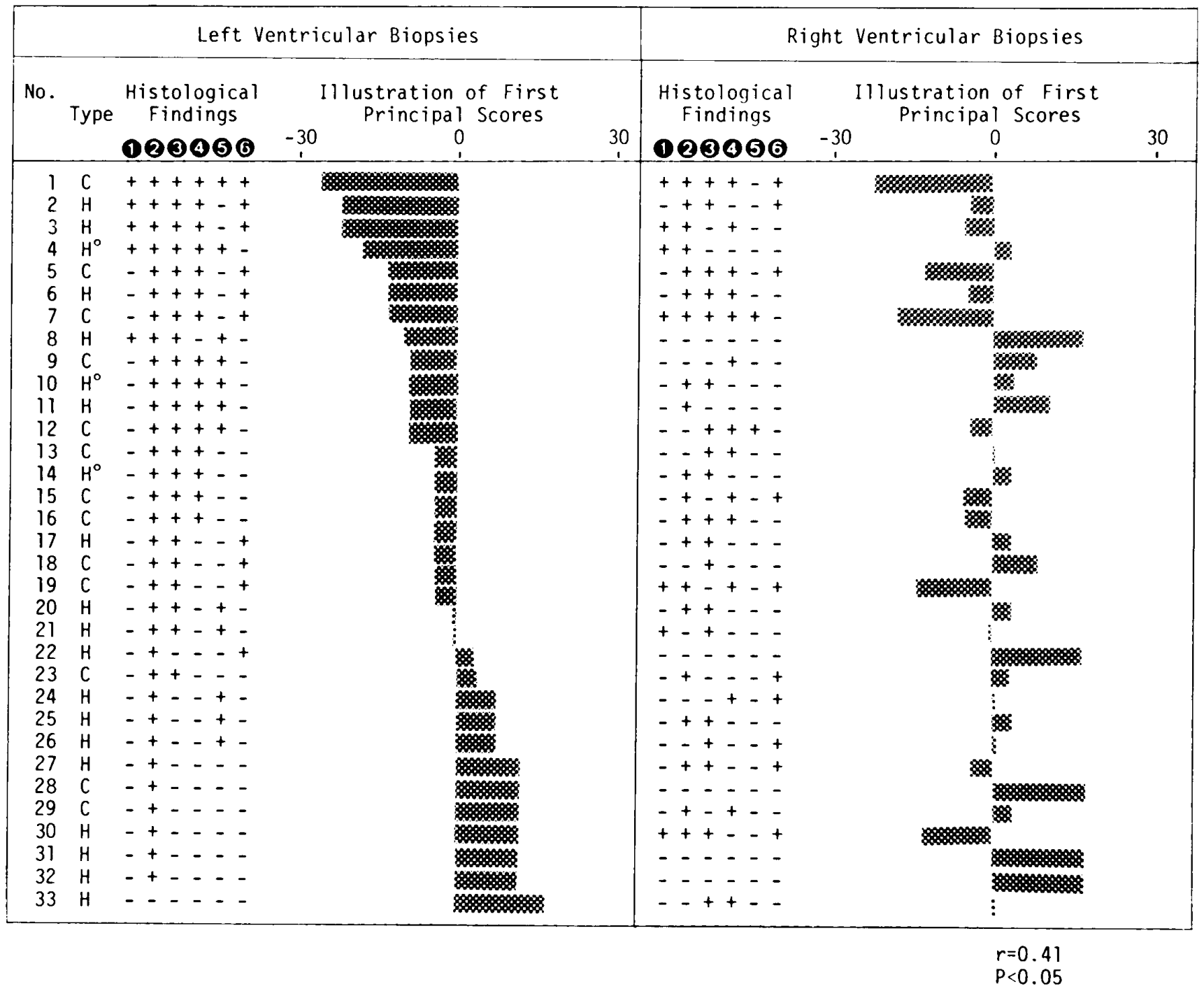

Fig.10. Correlation of histological changes in LVB and RVB for the first principal component. There is a positive correlation of the first principal scores between LVB and RVB obtained from the same heart $(\mathrm{r}=0.41, \mathrm{P}<0.05)$. Original categories $(+$ or -$)$ of myofiber hypertrophy (2) and vacuolization (5) reveal that these changes are more frequent in LVB than in RVB. $\mathrm{H}=$ hypertrophic non-obstructive cardiomyopathy, $\mathrm{H}^{\circ}=$ hypertrophic obstructive cardiomyopathy, $\mathrm{C}=$ congestive cardiomyopathy.

Comparison of histological changes between survivors and fatal cases, utilizing principal scores of LVB or RVB

Fig. 8 shows the average scores of LVB or RVB from survivors or fatal cases for the first, second and third principal components and their 95 percent confidence intervals. In LVB the difference was significant between survivors and fatal cases for the first and second principal components at the 5 percent level. In RVB the difference was also significant between these two groups for the first principal component at the 5 percent level. In both LVB and RVB the average value of the first principal scores is smaller in fatal cases than in survivors, which means that the histological changes in ventricular biopsies from the fatal cases are more severe than those from survivors (Figs. 4-A, $8 \&$ 9). For the second principal component, the mean value of LVB from fatal cases is smaller than that of LVB from survivors; i.e. proliferation of collagen fibers is more prominent and vacuolization less frequent in fatal cases than in survivors (Figs. 4-B, 8 \& 9).

Correlation of histological findings between LVB and RVB from the same patient with ICM

In 33 cases both left and right ventricular biopsies were examined and the histological findings correlated. Fig. 10 shows the correlation of 
six histological findings of LVB and RVB in which the first principal scores of both ventricular biopsies are compared. The first principal score of LVB is positively correlated with that of RVB $(r=0.41, P<0.05)$, which means that the over all histological changes of LVB correlate well with those of RVB; moreover, each histological feature of LVB correlates positively with that of RVB. However, there are some histological differences between LVB and RVB. As shown in Fig. 10 , both hypertrophy of myofibers and vacuolization are more frequent in LVB than in RVB, which are statistically evaluated for the second and third principal components at the 5 percent level.

\section{DISCUSSION}

\section{Univariate analysis}

Univariate analysis of histological findings be. tween HCM and CCM revealed no significant difference except in nuclear changes, which were more prominent in CCM than in HCM. Many investigators have reported that the nuclei of hypertrophied myocardial cells in several cardiac disorders manifest electron-microscopically infold ings or convolutions of nuclear membrane, pseudoinclusions and intranuclear tubules, and that these nuclear changes seem to be more severe and complicated in ICM than in other heart diseases. ${ }^{49}$ Moreover, in the myocardium of the interventricular septum in cases of HOCM large, bizarre nuclei associated with perinuclear vacuoles were frequently observed and considered to be specific for HOCM9,16,21,26,27 In this study, LVB in 4 cases of HOCM revealed moderate (gr. $2+$ in 3 cases) or marked (gr. $3+$ in one case) nuclear changes, in 3 of which there was also perinuclear vacuolization. On the other hand, RVB in 7 cases of HOCM manifested no apparent (in 3 cases), mild (gr. $1+$ in 2 cases) or moderate (gr. $2+$ in 2 cases) nuclear changes, all of which were associated with insignificant (gr. - in 2 cases, gr. 1+ in 5 cases) perinuclear vacuolization. Biopsy or autopsy studies have shown that nuclear changes also seen in the myocardium in cases of CCM9,22,23,25 In this study, large and bizarre nuclei were usually observed in moderately or severely hypertrophied myocardium in both HCM and CCM, but in some myofibers in CCM, deformed nuclei without evidence of hypertrophy of myofibers were observed. Hypertrophy accompanied by dilatation of the myocardium, which is common in $\mathrm{CCM}$, results in normal wall thickness despite hypertrophy, this is recognized histologically by attenuation of the myofibers, particularly in the inner layers of the myocardium. As a result of this dilatation, the myocardial cell diameter is within the normal range, but nuclear changes of hypertrophy are evident ${ }^{50}$ Additionally, since degenerative changes of myofibers and collagenosis are often prominent in CCM, it is speculated that these intra- and extra-cellular changes in architecture may influence the morphology of nuclei of the myocardium in CCM.

As mentioned above, a comparison of the myofiber disarray between HCM and CCM revealed that there was no significant difference in either LVB or RVB. However, myofiber disarray in RVB in the ASH group, diagnosed by echocardiography, was observed more frequently than in CCM. These results agree with the report by Alexander et al ${ }^{29}$ that RVB was useful in the diagnosis of HOCM because of the presence of distinct myofiber disarray. It has been reported that in ASH with or without left ventricular outflow obstruction, bizarrely shaped and abnormally arranged myofibers were frequently observed in the interventricular septum6,10-13,15,32-36,51 Electron-microscopically, this peculiar structure of myofibers was defined as bizarrely shaped myocardial cells and extensive side-to-side intercellular connections associated with disorientation of myofibrils and widened $Z$ bands. ${ }^{10-12}$, $15,29,35,36$ However there has been much doubt as to the specificity of these structures for ASH; for instance, similar myofiber disarray in ASH was found in some congenital cardiac malformations, ${ }^{52-55}$ even in developing normal heart 53,56 Noda et al ${ }^{57}$ noted that these bizarrely shaped and disarrayed myocardial cells were often seen in endomyocardial biopsies from CCM as well as from ASH pts, in which electron-microscopically peculiar polyhedral or trident intercellular connections were observed, with or without extensive side-to-side intercellular connections, but the specificity of these structures for ASH or CCM remains to be determined. As the authors ${ }^{52-56}$ commented, myofiber disarray may not be a characteristic feature of the myocardium in HOCM or ASH, but the predominance in topography and greater severity of myofiber disarray in HOCM than in other heart diseases has been reported in precise autopsy studies ${ }^{5-61}$ Maron et al., with a quantitative method, compared the areas of myocardium occupied by disorganized cells in the ventricular septum between patients 
with HCM and control subjects and concluded that widespread distribution of this abnormality was a very sensitive and specific histologic marker for HCM. Recently, Fujiwara et al61 examined thicker sections $(25 \mu \mathrm{m})$ of the hearts with HCM and suggested that usual fiber disarray reported in cases of HCM was actually a fascicle disarray with a three-dimensional complex network.

\section{Multivariate Analysis}

Generally speaking, multivariate analysis is utilized to understand a phenomenon influenced by multiple factors. For example, risk factors for coronary heart disease, , $^{64}$ prognosis of gastric cancer ${ }^{42}$ and factors influencing atherosclerosis $^{65}$ can be quantified by multivariate analysis. In this study, the first six histological findings listed above were selected and examined by means of categorical principal component analysis, one form of multivariate statistical analysis. For easy interpretation of the analytical results, graded scores of five degrees were divided into two categories, $(+)$ and $(-)$. Disarray of myofibers graded $(3+)$ or $(4+)$ was defined as category $(+)$, since disarray graded $(1+)$ or $(2+)$ was often observed in endomyocardial or open heart biopsies in other heart diseases, such as congenital or valvular heart diseases, ${ }^{66}$ so was considered to be non-specific.

In principal component analysis, for example, of men's bodies, the first principal component might express the size of the body, i.e. tall or short, heavy or light, which is called 'size factor'. The second or third principal component might represent shape, i.e. slender or fat and is called 'shape factor'43,46 In this study, the first principal component was characterized by all six histological findings which revealed 'severity' of histological changes. According to this first principal score, all cases of ICM could be roughly divided into two groups, one with severe histological changes, and one with no apparent histological change except hypertrophy of myofibers. Cases of HCM and CCM were in the former group, whereas the majority of cases in the latter group were HCM. Could the former be called "degeneration-dominant group", and the latter "hypertrophy-dominant group"? Similar results were reported by Sekiguchi et al. in a study of endomyocardial biopsies of ICM $^{20,22}$

Comparison of histological changes between HCM and CCM for the first principal component revealed that histological changes appeared more severe and complicated in CCM than in HCM in either LVB or RVB. There have been no reports of comparative quantitative studies of the myocardial histology in HCM and CCM. However, according to several reports, the histological characteristics of the myocardium in CCM are of various kinds: intramural thrombi, endocardial thickening, interstitial fibrosis, hypertrophy of myofibers, myofibrillolysis, nuclear changes, vacuolization, deposits of degenerative substance and so on, which often coexist9, 10-12,16,20-23 On the other hand, the histological findings of the myocardium in HCM are not so complex: hypertrophied myofibers with or without disorientation, large, deformed nuclei, perinuclear vacuoles and sometimes interstitial fibrosis?, $10-12,15,16,20-22,35$ The results of this study provide quantitative and statistical support to these qualitative observations.

A comparison of histological findings of the myocardium in survivors and fatal cases revealed that the histological changes in both LVB and RVB were more severe in the latter. This greater severity of histological changes in poor risk pts was more prominent in LVB, as mentioned above. These patients belonged to the group with severe histological changes as the first principal component. Kunkel et al. ${ }^{25}$ divided 66 CCM pts clinically and hemodynamically into two groups: early and advanced CCM. Their comparative and quantitative study of myofiber hypertrophy and interstitial fibrosis in the endomyocardial biopsies from these two groups revealed that both hypertrophy and fibrosis were more prominent in advanced CCM than in early CCM pts. Similar results were reported by Hiroe $^{27}$ and Davie ${ }^{28}$ and electron-microscopically by Kuhn ${ }^{24}$ and Sekiguchi ${ }^{31}$ These reports and the present study suggest that endomyocardial biopsy may be useful, to a certain extent, in the prognosis of ICM.

It has been generally accepted that vacuolization of myofibers is considered to be degeneration and may be called vacuolar degeneration or hydropic degeneration, ${ }^{39,67}$ A comparative study of the second principal component revealed that the myocardium of fatal cases had more prominent collagenosis but less severe vacuolization. Additionally, in the surviving group, biopsies with prominent fibrosis had no apparent vacuolization, whereas those with vacuolization had no significant fibrosis. It is speculated that one of the early changes of the myocardium under some conditions may be vacuolization in 
the sarcoplasm. If these reactions or adaptations end in failure, subsequent degenerative changes which are leading to intercellular fibrosis through some processes may develop.

It has been reported that the histological changes in RVB and LVB from the same patient with ICM might resemble each other, ${ }^{27}$ but this comment was the author's impression and lacked objectivity. The present study with multivariate analysis of 33 pts with ICM showed a positive correlation of histological changes between LVB and RVB from the same heart and supports the previous reports and the authors' impressions. In spite of the correlation of the histological findings between LVB and RVB, there are some differences in myofiber hypertrophy and vacuolization. Similar results but without quantitation were reported by Brooksby et al $3^{30}$ who mentioned that histological changes, i.e. hypertrophy of myofibers, fibrosis, vacuolization and myofiber disarray in LVB seemed more severe than those in RVB in 6 out of 8 cases of ICM. In this study, myofiber hypertrophy was observed more frequently in LVB than in RVB, which might be in part due to the use of the same standard value of myofiber diameter, up to $16 \mu \mathrm{m}$ as normal, for detecting hypertrophy of myofibers in both LVB and RVB. It has been reported that even in normal hearts, the diameter of the myofibers in the left ventricle might be $2-3 \mu \mathrm{m}$ larger than that in the right ventricle ${ }^{27}$ Vacuolization was more prominent in LVB than in RVB, indicating that the myocardium of the left ventricle may be under more unfavorable stress than that of the right ventricle. It is well known that in ICM pts, especially in CCM pts, congestive heart failure often develops initially on the left side. The present results showed greater myofiber hypertrophy and vacuolization in LVB than in RVB, which lends support histologically to this clinical finding in ICM pts.

\section{SUMMARY}

In order to evaluate the histological changes in endomyocardial biopsies from 121 patients with idiopathic cardiomyopathy, quantitation of histological findings was performed and analysed by univariate and multivariate statistical analysis. Several findings, i.e. (1) disarray of myofibers, (2) hypertrophy of myofibers, (3) scarcity of myofibrils, (4) nuclear changes, (5) vacuolization, (6) proliferation of collagen fibers, (7) endocardial thickening, (8) interstitial edema, (9) cell infiltration, (10) fatty infiltration and
(11) basophile degeneration, were graded in five degrees $(-$ to $4+)$ or two degrees $(-$ or +$)$ depending upon the severity and the extent of each finding. The univariate analysis of the graded histological findings revealed no remarkable difference between the biopsies from HCM and CCM pts, except for nuclear changes, which appeared to be more prevalent in $\mathrm{CCM}(\mathrm{p}<$ 0.05 ). In the categorical principal component analysis of the first six histological findings listed above, three principal components could be extracted. The first principal component was characterized by all six histological findings, the second by vacuolization and proliferation of collagen fibers, and the third by hypertrophy of myofibers. The mean values of the first principal scores indicated that, in either LVB or RVB histological changes were more severe in CCM than in HCM, and in fatal cases than in survivors. The second principal scores indicated that fatal cases had more collagenosis but less severe vacuolization than survivors. The histological findings in RVB appeared to be significantly correlated $(r=0.41, p<0.05)$ with those in LVB obtained from the same heart, but some differences were noted, myofiber hypertrophy and vacuolization being more prominent in LVB than in RVB.

\section{Acknoledgements}

The author wishes to express the deepest gratitude to Prof. T. Takatsu and Asst. Prof. K. Kawamura, Osaka Medical College, for providing the opportunity for this study and giving encouragement and advise. Thanks are also extended to Mr. M. Goto and Mr. T. Inoue, Shionogi Statistic Center, Osaka, for their computer analyses and valuable suggestions on our material.

This study was partly supported by a grant from the Ministry of Health and Welfare of the Japanese Government for the survey on idiopathic cardiomyopathy in Japan.

\section{REFERENCES}

1. GOODWIN, J. F., GORDON, H., HOLLMAN, A., \& BISHOP, M. B.: Clinical aspects of cardiomyopathy. Br. Med.J. 1:69, 1961.

2. GOODWIN, J. F.: Cardiac function in primary myocardial disorders, Part I \& II. Br. Med. J. 1: $1527,1964$.

3. Special Disease Study Group by the Ministry of Health and Welfare of the Japanese Government: Guidance for the Diagnosis of Special Diseases. pp.45-49, 1975. (in Japanese)

4. TAKATSU, T.: Id iopathic cardiomyopathy. Jap. J. Med. 17: 157, 1978.

5. GOODWIN, J. F.: Congestive and hypertrophic cardiomyopathies. A decade of study. Lancet I: $731,1970$. 
6. TEARE, D.: Asymmetrical hypertrophy of the heart in young adults. Br. Heart J. 20: 1, 1958.

7. OKADA, R. \& NASU, T.: Id iopathic myocardiopathy and allied cardiac diseases in Japan. Pathol. Microbiol. 35: 56, 1970.

8. OKADA, R.: A morphological classification of the idiopathic myocardiopathy and allied cardiac diseases. Jap. Circ. J. 35: 755, 1971.

9. OLSEN, E. G. J.: Pathology of primary cardiomyopathies. Postgrad. Med. J. 48: 732, 1972.

10. ROBERTS, W. C. \& FERRANS, V. J.: Morphologic observations in the cardiomyopathies. Myocardial Diseases, ed. by N. O. Fowler, Grune \& Stratton, New York and London, 1973, pp.59115.

11. ROBERTS, W.C. \& FERRANS, V. J.: Pathological aspects of certain cardiomyopathies. Circ. Res. 34, 35 Suppl. II: 128, 1974.

12. ROBERTS, W. C. \& FERRANS, V. J.: Pathologic anatomy of the cardiomyopathies; Id iopathic dilated and hypertrophic types, infiltrative types, and endomyocardial disease with and without eosinophilia. Hum. Pathol. 6: 287, 1975.

13. SUGAI, M., KONO, R., NAKAHARA, Y., KUNITA, Y. \& TANAKA, S.: Morphological observation of idiopathic cardiomyopathy consisting of 9 cases encountered in sudden and unexpected death. Acta Pathol. Jap. 27: 185, 1977.

14. TAKESHITA, I.: Clinical and histopathological study of idiopathic cardiomyopathy. Jap. Circ. J. 40: 1047, 1976. (in Japanese)

15. FERRANS, V. J., MORROW, A. G. \& ROBERTS, W. C.: Myocardial ultrastructure in idiopathic hypertrophic subaortic stenosis. A study of operatively excised left ventricular outflow tract muscle in 14 patients. Circulation 45: 769, 1972.

16. OLSEN, E. G. J.: Pathology of hypertrophic obstructive cardiomyopathy. Recent Advances in Studies on Cardiac Structure and Metabolism, Vol. 2, The Cardiomyopathies, ed. by E. Bajusz, G. Rona, A. J. Brink \& A. Lochner, University Park Press, Baltimore, 1973, pp.197-212.

17. SAKAKIBARA, S. \& KONNO, S.: Endomyocardial biopsy. Jap. Heart J. 3: 537, 1962.

18. KAWAMURA, K. \& HAYASHI, K.: Symposium on idiopathic myocardial fibrosis and allied diseases. 1. Ultrastructural aspects of myocardial diseases of unknown etiology. Jap. Circ. J. 30: $1575,1966$.

19. TAKATSU, T., KAWAI, C., TSUTSUMI, J. \& INOUE, K.: A case of idiopathic myocardiopathy with deposits of a peculiar substance in the myocardium; diagnosis by endomyocardial biopsy. Am. Heart J. 76: 93, 1968.

20. SEKIGUCHI, M. \& KONNO, S.: Histopathological differentiation employing endomyocardial biopsy in the clinical assessment of primary myocardial disease. Jap. Heart J. 10: 30, 1969.

21. VAN NOORDEN, S., OLSEN, E. G. J. \& PEARSE, G. E.: Hypertrophic obstructive cardiomyopathy, a histological, histochemical, and ultrastructural study of biopsy material. Cardiovasc. Res. 5: 118, 1971.

22. SEKIGUCHI, M. \& KONNO, S.: Diagnosis and classification of primary myocardial disease with the aid of endomyocardial biopsy. Jap. Circ. J. 35:
737,1971

23. SOMERS, K., HUTT, M. S. R., PATEL, A. K., \& D'ARBELA, P. G.: Endomyocardial biopsy in diagnosis of cardiomyopathies. Br. Heart J. 33: $822,1971$.

24. KUHN, H., BREITHARDT, G., KNIERIEM, H.-J., LOOGEN, F., BOTH, A., SCHMIDT, W. A. K., STROOBANDT, R., \& GLEICHMANN, U.: Die Bedeutung der endomyokardialen Katheterbiopsie für die Diagnostik und die Beurteilung der Prognose der kongestiven Kardiomyopathie. Dtsch. Med. Wochenschr. 100: 717, 1975.

25: KUNKEL, B., LAPP, H., KOBER, G., \& KALTENBACH, M.: Light-microscopic evaluation of myocardial biopsies. Cardiomyopathy and Myocardial Biopsy, ed. by M. Kaltenbach, F. Loogen \& E. G. J. Olsen, Springer-Verlag, Berlin, 1978, pp.62-70.

26. OLSEN, E. G. J.: Postmortem findings and histologic, histochemical, and electron microscopic findings of myocardial biopsies. Cardiomyopathy and Myocardial Biopsy, ed. by M. Kaltenbach, F. Loogen \& E. G. J. Olsen, Springer-Verlag, Berlin, 1978, pp.52-61.

27. HIROE, M., SEKIGUCHI, M., HAZE, K., \& HIROSAWA, K.: Clinical assessment of the severity of cardiomyopathic patients employing endomyocardial biospy. Saishin-Igaku 32: 78, 1977. (in Japanese)

28. DAVIES, M. J., BROOKSBY, I. A. B., JENKINS, B. S., CANKOVIC-DARRACOTT, B., SWANTON, R. H., COLTART, D. J., \& WEBB-PEPLOE, M. M.: Left ventricular endomyocardial biospy II: The value of light microscopy. Catheter. Cardiovasc. Diagn. 3: 123, 1977.

29. ALEXANDER, C. S. \& GOBEL, F. L.: Diagnosis of idiopathic hypertrophic subaortic stenosis by right ventricular septal biopsy. Am.J. Cardiol. 34: 142,1974

30. BROOKSBY, I. A. B., JENKINS, B. S., COLTART, D. J., WEBB-PEPLOE, M. M., \& DAVIES, M. J.: Left-ventricular endomyocardial biopsy. Lancet II: $1222,1974$.

31. SEKIGUCHI, M., HAZE, K., HIROE, M., KONNO, S., \& HIROSAWA, K.: Interrelation of left ventricular function and myocardial ultrastructure as assessed by endomyocardial biopsy: comparative study of hypertrophic and congestive cardiomyopathies. Recent Advances in Studies on Cardiac Structure and Metabolism, Vol.12, Cardiac Adaptation, ed. by T. Kobayashi, Y. Ito and G. Rona, University Park Press, Baltimore, 1978, pp.327334.

32. HENRY, W. L., CLARK, C. E., \& EPSTEIN, S. E.: Asymmetric septal hypertrophy. Echocardiographic identification of the pathognomonic anatomic abnormality of IHSS. Circulation 47: $225,1973$.

33. HENRY, W. L., CLARK, C. E., \& EPSTEIN, S. E.: Asymmetric septal hypertrophy (ASH): The unifying link in the IHSS disease spectrum. Observations regarding its pathogenesis, pathophysiology and course. Circulation 47: 827, 1973.

34. HENRY, W. L., CLARK, C. E., ROBERTS, W. C., MORROW, A. G., \& EPSTEIN, S. E.: Differences in distribution of myocardial abnormalities in patients with obstructive and nonobstructive asym- 
metric septal hypertrophy (ASH). Echocardiographic and gross anatomic findings. Circulation 50: 447, 1974.

35. MARON, B. J., FERRANS, V. J., HENRY, W. L., CLARK, C. E., REDWOOD, D. R., ROBERTS, W. C., MORROW, A. G., \& EPSTEIN, S. E.: Differences in distribution of myocardial abnormalities in patients with obstructive and nonobstructive asymmetric septal hypertrophy (ASH). Light and electron microscopic findings. Circulation 50: 436, 1974.

36. FERRANS, V. J., MASSUMI, R. A., SHUGOLL, G. I., ALI, N., \& ROBERTS, W. C.: Ultrastructural studies of myocardial biopsies in 45 patients with obstructive or congestive cardiomyopathy. Recent Advances in Studies on Cardiac Structure and Metabolism, Vol.2, The Cardiomyopathies, ed. by E. Bajusz, G. Rona, A. J. Brink \& A. Lochner, University Park Press, Baltimore, 1973, pp.231272.

37. SEKIGUCHI, M.: Electron microscopical observations of the myocardium in patients with idiopathic cardiomyopathy using endomyocardial biopsy. J. Mol. Cell. Cardiol. 6: 111, 1974.

38. KARESNER, H. T., SAPHIR, O., \& TODD, T. W.: The state of the cardiac muscle in hypertrophy and atrophy. Am. J. Pathol. 1: 351, 1925.

39. LINZBACH, A. J.: Mikrometrische und histologische Analyse hypertropher menschlicher Herzen. Virchows Arch. Pathol. Anat. 314: 534, 1947.

40. HENSCHEL, E.: Über Muskelfasermessungen und Kernveränderungen bei numerischer Hyperplasie des Myokards. Virchows Arch. Pathol. Anat. 321: 283, 1952.

41. OKADA, R.: Clinicopathological study of the thickening of parietal endocardium in the adult heart. Jap. Heart J. 2: 220, 1961.

42. GOTO, M., MATSUBARA, Y., NAKAZATO, H., \& ASANO, C.: Statistical evaluation of influencing factors on prognosis of gastric cancer patients. Behaviormetrika 4: 13, 1977.

43. GOTO, M. \& KODAMA, H.: Multivariate analysis. Gendai-Sügaku, 9: 21, 1976. (in Japanese)

44. HOPE, K.: Methods of multivariate analysis. University of London, Athlone Press, London, 1968, pp.40-67.

45. MARRIOTT, F. H. C.: The interpretation of multiple observations. Academic Press, London, 1974, pp.18-25.

46. OKUNO, T., KUME, H., HAGA, T., \& YOSHIZAWA, T.: Multivariate statistical analy sis. NikkaGiren, 1971, pp.159-257. (in Japanese)

47. SAKAKIBARA, S., SEKIGUCHI, M., KONNO, S., \& KUSUMOTO, M.: Id iopathic postpartum cardiomyopathy: Report of a case with special reference to its ultrastructural changes in the myocardium as studied by endomyocardial biopsy. Am. Heart J. 80: 385, 1970.

48. FERRANS, V. J., HIBBS, R. G., WALSH, J. J., \& BURCH, G. E.: Cardiomyopathy, cirrhosis of the liver and deposits of a fibrillar polysaccharide. Report of case with histochemical and electron microscopic studies. Am. J. Cardiol. 17: 457, 1966.

49. FERRANS, V. J., JONES, M., MARON, B. J., \&
ROBERTS, W. C.: The nuclear membranes in hypertrophied human cardiac muscle cells. Am.J. Pathol. 78: 427, 1975.

50. OLSEN, E. G. J.: Structural and ultrastructural ba sis of myocardial disease. Proc. R. Soc. Med. 69: $195,1976$.

51. KNIERIEM, H. J., STROOBANDT, R., MEYER, H., \& BOURGEOIS, M.: Hypertrophic nonobstructive cardiomyopathy caused by disorder of the myofiber texture. Virchows Arch. Pathol. Anat. 367: 209, 1975.

52. BULKLEY, B. H., WEISFELDT, M. L., \& HUTCHINS, G. M.: Isometric cardiac contraction. A possible cause of the disorganized myocardial pattern of idiopathic hypertrophic subaortic stenosis. N. Engl. J. Med. 295: 135, 1977.

53. BULKLEY, B. H., WEISFELDT, M. L., \& HUTCHINS G. M.: Asymmetric septal hypertrophy and myocardial fiber disarray. Circulation 56: 292, 1977.

54. MARON, B. J., EDWARDS, J. E., FERRANS, V. J., CLARK, C. E., LEBOWITZ, E. A., HENRY, W. L., \& EPSTEIN, S. E.: Congenital heart malformations associated with disproportionate ventricular septal thickening. Circulation 52: 926. 1975.

55. MARON, B. J., FERRANS, V. J., \& WHITE, R. I.: Unusual evolution of acquired infundibular stenosis in patients with ventricular septal defect. Clinical and morphologic observations. Circulation 48: $1092,1973$.

56. MARON, B. J. \& VERTER, J.: Disproportionate ventricular septal thickening in the developing normal human heart. Circulation 57: 520, 1978.

57. NODA, S., IMAMURA, K., KITAURA, Y., KAWAMURA, K., \& TAKATSU, T.: Abnormal intercellular connections of myocardial cells in idiopathic cardiomyopathy; a light and electron microscopic study. J. Clin. Electron Microsc. 11 : 508, 1978.

58. VAN DER BEL-KAHN, J.: Muscle fiber disarray in common heart diseases. Am. J. Cardiol. 40: $355,1977$.

59. ST. JOHN SUTTON, M. G., ANDERSON, K. R., LIE, J. T., \& FRYE, R. L.: Specificity and topography of myocardial fiber disarray and fibrosis in hypertrophic obstructive cardiomyopathy (HOCM) (abstr.). Circulation 55, 56 Suppl. III: 205, 1977.

60. MARON, B. J. \& ROBERTS, W. C.: Quantitative analysis of cardiac muscle cell disorganization in the ventricular septum of patients with hypertrophic cardiomyopathy. Circulation 59: 689, 1979.

61. FUJIWARA, H., KAWAI, C., \& HAMASHIMA, Y.: Myocardial fascicle and fiber disarray in $25 \mu$-thick sections. Circulation 59: 1293, 1979.

62. WILHELMSEN, L., WEDEL, H., \& TIBBLIN, G.: Multivariate analysis of risk factors for coronary heart disease. Circulation 48: 950, 1973.

63. BRAND, R. J., ROSENMAN, R. H., SHOLTZ, R. I., \& FRIEDMAN, M.: Multivariate prediction of coronary heart disease in the Western Collaborative Group Study compared to the findings of the Framingham Study. Circulation 53: 348, 1976.

64. TRUETT, J., CORNFIELD, J., \& KANNEL, W.: A multivariate analysis of the risk of coronary heart disease in Framingham. J. Chronic. Dis. 20: $511,1967$. 
65. ORIMO, H., ITO, H., SHIRAI, M., OOYAMA, T., NAKANO, T., GOTO, I., HAYASHI, J., KAMBA, M., \& GOTO, M.: Atherosclerotic vascular lesions and impaired glucose tolerance in the aged. J. Jap. Diab. Soc. 21: 137, 1978. (in Japanese)

66. KAWAMURA, K., NODA, S., IMAMURA, K., UEHARA, H., KITAURA, Y., \& TAKATSU, T.:
Ultrastructure of myocardium in patients with hypertrophic cardiomyopathy. Internal Medicine Series, No.32, Idiopathic Cardiomyopathy, eg. by Kawai, C., Nankōdo, 1978, pp.68-86. (in Japanese) 67. SCOTTI, T. M.: Pathology, 7 th edition, Vol. I, ed. by Anderson, W. A. D. \& Kissance, J. M., The C. V. Mosby Company, Saint Louis, 1977, pp.738-746. 